\title{
Políticas sanitarias durante el Lencinismo (1918-1928). El proyecto de Hospital de niños de Mendoza
}

\author{
Natalia Mabel Luis* \\ Silvia Augusta Cirvini**
}

Recibido: 24 de septiembre de 2019

Dictaminado: 26 de marzo de 2020

Aceptado: 28 de agosto de 2020

\section{RESUMEN}

En este artículo se propone analizar la formulación de políticas públicas de salubridad en Mendoza durante el período de gobernaciones lencinistas (19181928). Estos gobiernos propusieron ampliar la infraestructura médico-sanitaria en la capital provincial y sostuvieron como prioridad su extensión y desarrollo en los departamentos de la periferia, con el fin de hacer accesible la asistencia a la población que residía en zonas alejadas. Particularmente, se expone el caso del proyecto de construcción de un hospital pediátrico ideado por el arquitecto Raúl Álvarez en 1927, propuesto como respuesta a la expansión de enfermedades con elevado índice de mortalidad infantil.

* Instituto de Ciencias Humanas, Sociales y Ambientales, Consejo Nacional de Investigaciones Científicas y Técnicas, Mendoza, Argentina.

Correo electrónico: nluis@mendoza-conicet.gob.ar ORCID: https://orcid.org/0000-0002-5745-907X

** Instituto de Ciencias Humanas, Sociales y Ambientales, Consejo Nacional de Investigaciones Científicas y Técnicas, Mendoza, Argentina.

Correo electrónico: scirvini@mendoza-conicet.gob.ar 
La producción arquitectónica derivada de estas políticas sanitarias estuvo vinculada a un cambio de modalidad en la relación entre técnica y política, por lo cual se promovió la realización de concursos y la contratación de profesionales para la realización de obras públicas, en un contexto signado por una mayor regulación del ejercicio de diferentes profesiones liberales (arquitectura, ingeniería, actividades curativas).

Se consultaron diversas fuentes: proyectos de ley y debates parlamentarios en los diarios de sesiones legislativas (Archivo de la Legislatura de Mendoza), prensa local de diverso signo: La Palabra, Los Andes, y El Socialista. Además, se utilizó la Memoria del Ministerio de Obras Públicas correspondiente a 1922-1923, la Memoria de la Dirección de Salubridad correspondiente a 1927 (Biblioteca Pública General San Martín), y anuarios estadísticos del período analizado (Dirección General de Estadísticas de Mendoza).

Palabras clave: Mendoza, Lencinismo, equipamiento sanitario, hospital, niños.

\title{
Health policies during Lencinism (1918-1928). The Mendoza children Hospital project
}

\begin{abstract}
This article proposes to analyze the formulation of public health policies in Mendoza during the period of Lencinist governments (1918-1928). These governments proposed to expand the medical-health infrastructure in the capital city and maintained as a priority their expansion and development to the peripheral cities, in order to make assistance possible to people living in remote areas. It particularly describes the case of the construction project of a pediatric hospital in 1927, proposed in response to the expansion of diseases with a high rate of child mortality.

The architectural production derived from these health policies was linked to a change in the way technique and politics were related, which promoted the organization of competitions and hiring professionals for the execution of public works, in a context signified by a greater regulation of the exercise of different liberal professions (architecture, engineering, healing activities).

Various sources were consulted: draft laws and parliamentary debates in the articles of legislative sessions (Archive of the Legislature of Mendoza), local press of various signs: La Palabra, Los Andes, and El Socialista. In addition, the Report of the Ministry of Public Works corresponding to 19221923, the Report of the Health Directorate corresponding to 1927 (Public Library General San Martín), and Statistical Yearbooks of the period analyzed (General Direction of Statistics of Mendoza) was used.
\end{abstract}

Key words: Mendoza, Lencinism, sanitary equipment, hospital, children. 
$E^{\prime}$ período histórico que se analiza en este artículo fue muy convulsionado a nivel político, ya que luego de una larga etapa de orden conservador, signada por el fraude electoral, entre fines del siglo xIx y comienzos del xx, nuevas olas de radicalización transformaron las prácticas políticas en Latinoamérica. En Argentina nació de la crisis de 1890 y tomó cuerpo con la Unión Cívica Radical (UCR) bajo el liderazgo de Hipólito Yrigoyen. En ese contexto fue particularmente importante la sanción de la Ley Electoral Sáenz Peña en 1912, que, al instaurar la obligatoriedad, el secreto del voto y la representación de la minoría permitió elecciones más transparentes que trajeron aparejado un proceso de democratización política que llevó en las elecciones de 1916 al gobierno nacional a la Unión Cívica Radical (en adelante UCR). ${ }^{1}$ Poco después se celebraron elecciones para gobernador en Mendoza y salió triunfante José Néstor Lencinas, de la UCR, quien asumió en 1918.

A partir de la consolidación de la estructura partidaria y su victoria electoral, el radicalismo construyó una identidad política y cultural que presentó como sus principales enemigos a los miembros de la oligarquía. ${ }^{2}$ José Néstor Lencinas y luego su hijo Carlos Washington Lencinas, lideraron lo que algunos autores llaman el "populismo mendocino". ${ }^{3}$ Apenas asumió José Néstor Lencinas el cargo de gobernador, se produjo una división entre radicales y lencinistas. Éstos coincidían en su proyecto de reformas sociales, pero los radicales yrigoyenistas eran reformistas, partidarios de cambios moderados, y Lencinas era revolucionario, decidido a alterar el sistema. ${ }^{4}$

Durante el período lencinista (1918-1928), hubo tres gobernaciones y cuatro intervenciones federales, lo que generó escasa continuidad de las propuestas políticas en marcha. Las gobernaciones, todas interrumpidas por el gobierno federal, estuvieron encabezadas por José Néstor Lencinas (19181920); Carlos Washington (1922-1924); y por Alejandro Orfila (1926-1928). A la inestabilidad política, se sumó la inestabilidad económica ${ }^{5}$ (se alternó una

Para ampliar información consultar: Persello, Historia del radicalismo, pp. 51-69.

Mellado, "La Liga Patriótica Argentina", p. 18.

Los autores caracterizan al lencinismo como un caso de populismo cuyano, junto al cantonismo de San Juan. Para ampliar información consultar: Richard Jorba, "Los gobiernos radicales de los Lencinas en Mendoza"; Richard Jorba, "Los orígenes del fenómeno populista en Mendoza"; Rodríguez, Lencinas y Cantoni; Lacoste, La Unión Cívica Radical en Mendoza y en la Argentina.

Richard Jorba aclara al respecto que en los populismos hay una presencia excluyente de las categorías pueblo y patria como una totalidad cuya representación asume el movimiento político, excluyendo a quienes no comparten esa visión, con lo cual se transforman en el antipueblo y la antipatria, de lo que deriva la aplicación de la lógica amigo/enemigo — con su carga violenta - a las relaciones políticas. Cfr: Richard Jorba, "Los gobiernos radicales de los Lencinas en Mendoza", p. 21.

$4 \quad$ Lacoste, La Unión Cívica Radical en Mendoza y en la Argentina, p. 72.

5 Para ampliar, consultar: Barrio, "Finanzas públicas y vitivinicultura durante el lencinismo"; y Barrio, "Regulación e intervención estatal en tiempos turbulentos". 
época de auge a la que siguió una crisis financiera), que conllevó a que muchos de los planes ideados por los dirigentes lencinistas no pudieran concretarse o se retrasara su ejecución.

Es importante mencionar, además, que durante ese lapso temporal se reglamentó la práctica profesional. Por un lado, se normó de manera más rigurosa la medicina, obstetricia y farmacia mediante la reforma de la Ley sanitaria en 1927, y por otro, hubo un proyecto de ley que proponía reglamentar las carreras de arquitectura, ingeniería y agrimensura en 1922, que, si bien no se sancionó, da cuenta del avance del Estado provincial en la reglamentación del ejercicio profesional en un contexto de incremento de la profesionalización del Estado, que acudía más asiduamente a personal técnico para que ocupara los puestos de la administración pública. ${ }^{6}$ Entonces, el Estado provincial no sólo recurría a personal especializado para la ejecución de las obras, sino que pretendía garantizar el correcto ejercicio de las profesiones para toda la población, monopolizando la legitimación de sus títulos y su saber, produciéndose una relación dialéctica que redundaba en la consolidación e institucionalización de ambos, saberes y Estado.

En ese marco, durante 1918 y 1928 el discurso antioligárquico y el contacto con las masas se tradujeron en el uso del espacio público, que incluyó escenarios de participación para actores de la clase media y sectores populares, en ámbitos que antes eran exclusividad de las élites y sectores dirigentes. Durante ese período se mejoró la infraestructura sanitaria, como se detalla en el próximo apartado.

Es amplia la bibliografía que considera el estado sanitario a comienzos del siglo Xx en América Latina y Argentina. La mayoría de los trabajos estudian las enfermedades epidémicas y analizan cómo desde el Estado se implementaron políticas públicas para combatirlas, de acuerdo con los principios higienistas. ${ }^{8}$

6 Es cada vez más diversificada la producción historiográfica sobre los procesos de institucionalización de algunas disciplinas y la relación de los expertos con un sistema internacional que los legitima. Se destacan, entre otros, los libros compilados en 2012 por Ben Plotkin, y Zimmermann, Los saberes del Estado; y Las prácticas del Estado. Para el caso de Mendoza está Rodríguez Vázquez, y Raffa, Profesionalizando un Estado provincial. Cfr. para ampliar, consultar: Luis, La alpargata en el espacio público.

$8 \quad$ Al respecto se pueden mencionar los trabajos de Armus, "El descubrimiento de la enfermedad", y La ciudad impura; Carbonetti, "Historia de una epidemia olvidada", y "Las epidemias de cólera en Córdoba a través del periodismo"; Álvarez, "De la higiene pública a la higiene social en Buenos Aires", y "La aparición del cólera en Buenos Aires"; y el reciente libro coordinado por la misma autora, en el que se exponen diversos trabajos sobre la historia de la salud que visibilizan las diversas líneas de investigación y temáticas, y los diferentes repositorios documentales que es posible consultar. Cfr. Álvarez, Historia de la salud y la enfermedad. 
Otros autores se centran en la profesionalización de la salud y el surgimiento de las actividades curativas como profesión. ${ }^{9}$

En Mendoza, Cirvini, Ponte, Raffa y Aguerregaray analizan la salubridad provincial entre fines del siglo XIX y comienzos del xx y aluden a las medidas implementadas por los dirigentes para mejorar las condiciones sanitarias de la ciudad. ${ }^{10}$ Por otro lado, hay textos que consideran las políticas públicas implementadas en el campo de la salud en la provincia, como los de Hirschegger y los de Raffa, ${ }^{11}$ pero no se refieren particularmente a los primeros años del siglo xx. Luis y Aguerregary, por su parte, abordan la expansión y profesionalización del sistema de salud a fines del siglo XIX y principios del XX, centrándose en las modificaciones producidas a nivel discursivo, que tuvieron su correlato en la aplicación de medidas sanitarias. ${ }^{12}$ Por otro lado, Richard Jorba, estudia las condiciones de vida de los sectores populares durante el período lencinista centrándose en las políticas de salud y de vivienda implementadas. ${ }^{13}$ No obstante, el autor abarca las dos primeras gestiones gubernamentales, por lo cual el resto del período constituye una temática vacante que el presente artículo se propone analizar.

\section{Población y estado sanitario de Mendoza entre fines del SIGLO XIX Y COMIENZOS DEL XX}

Hacia fines del siglo XIX y principios del XX a nivel mundial, las enfermedades infectocontagiosas devinieron en un problema social. Por ello comenzó a considerárseles un asunto en el que el Estado debía intervenir, y una necesidad primordial el tratar de evitarlas por medio de políticas públicas. ${ }^{14}$ En Argentina, tanto a nivel nacional como provincial se convocó a médicos higienistas para que realizaran informes dedicados a estudiar las causas de las enfermedades y a proponer medidas preventivas con el fin de mejorar la infraestructura. ${ }^{15}$

9 Destaca, entre otros, la compilación "La salud pública y la enfermería en la Argentina", de Biernat, Cerdá y Ramacciotti, quienes trabajan los vínculos entre la profesión médica, la política y la gestión pública, y reconstruyen los primeros pasos de la historia de la enfermería como profesión; y los artículos del dossier coordinado por Ramacciotti, "La profesionalización del cuidado sanitario. La enfermería en la historia argentina".

10 Cirvini, "el ambiente urbano en Mendoza"; Ponte, La Fragilidad de la memoria; Raffa, "El imaginario sanitario en Mendoza"; y Aguerregaray, Representaciones y prácticas de la muerte.

11 Cfr. Raffa, "Políticas sanitarias y arquitectura de Estado en Mendoza", Hirschegger, "La Salud Pública frente a un Estado centralizado" y Hirschegger "La Escuela Mixta de Enfermeros de 1942 ".

12 Cfr. Luis y Aguerregary, "De "culpables" a "víctimas".

13 Richard Jorba, "Los gobiernos radicales de los Lencinas".

14 Armus, "El descubrimiento de la enfermedad como problema social", p. 511.

15 En Mendoza, a causa de la epidemia de cólera que afectó la ciudad entre noviembre de 1866 
Las tareas sanitarias que se llevaron a cabo en este período en las principales ciudades argentinas estuvieron centradas en la provisión de agua potable y la eliminación de desechos; la especificación y ampliación de los reglamentos de control de las industrias; el alejamiento del centro urbano y la reglamentación de los espacios calificados como peligrosos, como los cementerios; la delineación de calles y la creación de espacios verdes, entre algunos de los aspectos considerados. Particularmente en Mendoza fue fundamental extender el servicio de agua potable, ya que las acequias características de la cuidad eran utilizadas al mismo tiempo tanto para provisión de líquido como para desagüe, lo que generó una gran contaminación de éstas, constituyendo una fuente de propagación de enfermedades.

De hecho, la provincia andina fue ámbito propicio de numerosas enfermedades epidémicas (cólera, difteria, escarlatina, gripe, tuberculosis, entre otras), y muchos casos de otras afecciones basadas en las deficiencias sanitarias, como la gastroenteritis. Esta situación crítica estaba relacionada con el acentuado crecimiento demográfico y urbanístico producido desde 1885, a partir de la instalación y desarrollo del ferrocarril y la inmigración, ${ }^{16}$ cuando no se disponían de los medios materiales necesarios para garantizar en la ciudad un entorno sanitario adecuado. A esto se sumaba las deplorables condiciones higiénicas en las que se encontraba la ciudad antigua, la cual había sido desatendida por los gobiernos desde la reconstrucción posterior al terremoto de $1861 .{ }^{17}$ Así, la situación sanitaria de Mendoza era muy deficiente a finales del siglo XIX.

y marzo de 1867, se formó la Comisión de Higiene. Puiggari, Ramos Mejía, Nyströmer, Rawson, Wilde y Coni, fueron algunos de los profesionales que publicaron una serie de escritos sobre higiene en general (Wilde, Higiene Pública, 1885) y sobre casos específicos de aplicación (Rawson, Estudio sobre las casas de inquilinato, 1884). José Salas, publicó en 1889 Breves Consideraciones Higiénicas sobre la Ciudad de Mendoza, libro que muestra la visión higienista finisecular (al menos una versión de ella) sobre Mendoza y los mendocinos, luego de su paso como "Inspector de muertos" en la gestión municipal de Luis Lagomaggiore (1884-1888). En Raffa, "El imaginario sanitario en Mendoza", p.176.

16 Juan Manuel Cerdá explica cómo la incorporación de un número significativo de inmigrantes a finales del siglo XIX, junto a un proceso de reorganización productiva asociado al desarrollo de la industria vitivinícola implicó cambios en las relaciones sociales y en las condiciones de vida de amplios sectores de la población mendocina. Particularmente, señala que los trabajadores pasaron por períodos de alta precariedad e inestabilidad en sus trabajos, aspecto que afectó directamente sus condiciones de vida. Para ampliar información Cfr. Cerdá, "Mercado de trabajo y condiciones de vida en Mendoza", http://www.mundoagrario.unlp. edu.ar/

17 En 1861 la provincia sufrió un terremoto que destruyó casi por completo las estructuras edilicias. La ciudad "nueva" se reconstruyó al oeste de la antigua, dejando ese sitio lleno de escombros. Las autoridades municipales y provinciales no consideraban la sección Este 
Luego de la epidemia de cólera (1886-1887) se dieron modificaciones que buscaron preservar la salud de la población a través de la aplicación de una serie de normas y estrategias planificadas (basadas en la prevención y la vigilancia) y de la inversión en obras sanitarias, tales como la ampliación del servicio de agua potable, el control sobre los establecimientos públicos (matadero, mercado, casa de baños públicos, cementerio), la construcción de un Lazareto para aislamiento de los infectocontagiosos y la obligatoriedad de la vacunación antivariólica (1889). ${ }^{18}$

En esa época, el organismo encargado de regular e implementar medidas sanitarias era el Consejo Provincial de Higiene, creado en 1891. Posteriormente, en 1897, se creó la Dirección Provincial de Salubridad, institución que dependía del Ministerio de Obras Públicas de la provincia. Ésta actuó durante la primera mitad del siglo xx. Se ocupaba de todo lo relativo a la higiene y salud pública, a la inspección y vigilancia de las aguas, a la vacunación antivariólica, a la profilaxis de enfermedades infectocontagiosas, epidemias, epizootias y epifitas, además, debía encargarse de los nosocomios y del transporte de infectocontagiosos, la desinfección de cementerios y la inspección de las inhumaciones. Asimismo, podía dictar disposiciones de carácter general y local que tendrían carácter de ley, siempre que las circunstancias lo requirieran, como en el caso de las epidemias. ${ }^{19}$

Ahora bien, a principios del siglo xx (al 31 de diciembre de 1900) Mendoza tenía 133408 habitantes. En 1914 contaba con 283 640. Éstos estaban concentrados en los principales centros urbanos. En la Capital habitaban 59117 personas, lo cual representaba un 20.84\% del total (Ilustración 1). En 1918, año en que comenzaron a gobernar los lencinistas, la provincia tenía 304323 habitantes, y diez años después ya contaba con 401024 (Anuario estadístico 1927-1930).

Desde fines del siglo xIx, Mendoza recibía un alto porcentaje de inmigrantes. En 1914, entre el 1 de junio y el 31 de diciembre, ingresaron a la provincia 1269 inmigrantes y el total de extranjeros en la provincia era de 88354 , representando más del $30 \%$ de la población provincial ${ }^{20}$ (Anuario estadístico 1914, DGEM y Tercer Censo Nacional, pp. 314-315).

como una prioridad en materia de servicios, con lo cual se fue generando una segregación socio espacial en torno a la ciudad antigua. Para ampliar información consultar: Luis, $L a$ alpargata en el espacio público, pp.162-167.

18 Cirvini, op. cit. "El ambiente urbano en Mendoza".

19 Ley y reglamentos relativos a sanidad e higiene pública de la provincia, 1897, p. 6. Para ampliar información consultar: Aguerregaray, Representaciones y prácticas de la muerte, p. 72 .

20 Al finalizar la Primera Guerra Mundial el número de inmigrantes radicados en la provincia descendió y a excepción del año 1927 no volvió a tener la dimensión de años anteriores. 


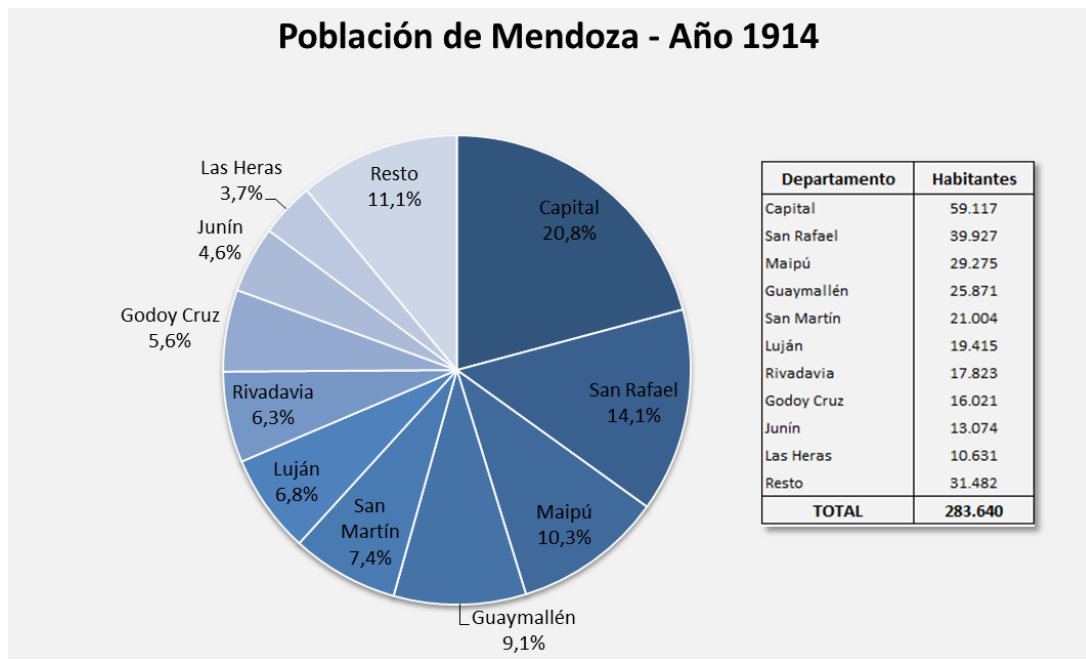

Ilustración 1. Población de Mendoza por departamento, 1914.

Fuente: elaboración propia en base a los datos estadísticos del año 1914 (DGEM).

En relación con el estado sanitario, si bien a fines del siglo XIX se habían implementado algunas medidas, como se expuso, a comienzos del siglo xx el periódico Los Andes ${ }^{21}$ manifestaba que era lamentable el estado sanitario de la provincia, ya que las enfermedades infectocontagiosas continuaban siendo endémicas y epidémicas; además, la población de recién nacidos y los menores de 5 años eran los más afectados. ${ }^{22}$

Durante el período lencinista se implementaron medidas que mejoraron la salubridad provincial, por un lado, se amplió el servicio de agua potable, se proyectó la red de cloacas en la capital mendocina, y se extendió el servicio de agua corriente hacia varios departamentos, ${ }^{23}$ medidas que mejoraron de manera significativa la calidad del ambiente urbano provincial. Sumado a esto, los dirigentes se propusieron mejorar y ampliar la asistencia médica, tal como se expone a continuación.

El diario Los Andes fue fundado, en 1882, por Adolfo Calle, y es un ejemplo de periodismo de empresa. Tenía una tendencia ideológica liberal.

22 Cfr. Ponte, op. cit. La Fragilidad de la Memoria, p. 233.

23 Durante el período 1918-1828 se logró aprobar los convenios para explotar y extender el servicio de agua potable a los departamentos de San Rafael, San Martín, Rivadavia, Junín, Tunuyán, Las Heras y General Alvear, que vendrían a sumarse a Maipú y Godoy Cruz y Luján, departamentos en los cuales se había extendido el servicio con anterioridad. Para ampliar información consultar: Luis, “Agua potable y red cloacal”, pp. 115-153. 


\section{ASISTENCIA MÉDICA ESTATAL EN LA DÉCADA LENCINISTA}

Con anterioridad a las gobernaciones lencinistas existían algunos hospitales estatales como el San Antonio ${ }^{24}$ (1761) y el Hospital Provincial ${ }^{25}$ (primer hospital moderno de Mendoza, inaugurado en 1907 y dedicado a la atención de hombres, mujeres y niños). Además, en los departamentos estaba el Hospital el Carmen (1900) en Godoy Cruz, el Hospital de General Alvear ("Hospital Municipal", fundado en 1912, en 1923 ya contaba con 26 camas), y se había comenzado a construir el Hospital de Maipú y el de San Martín, que fueron finalizados e inaugurados por José Néstor Lencinas. Si bien estos centros asistenciales atendían también a menores, no se dedicaban especialmente a infantes.

Durante el período de gobernaciones lencinistas se mejoró la atención médica en la Capital y se extendió a varios departamentos, ${ }^{26}$ efectivizando la descentralización geográfica iniciada con los gobiernos conservadores. ${ }^{27}$

Entre otras medidas los dirigentes se propusieron construir una casa de aislamiento para atender a los que padecían enfermedad infectocontagiosa, especialmente tuberculosis, una de las epidemias de la época. ${ }^{28}$ En 1919 se encargó a Raúl Álvarez (arquitecto que realizó importantes obras durante el período, como se desarrolla a continuación) que proyectara el Hospital José

24 El primer hospital que tuvo Mendoza fue el "San Antonio" (1761), doscientos años después de la fundación de la ciudad. Este primer establecimiento fue creado y dirigido por la orden de los betlemitas, venidos del Perú a fines del XVIII expresamente para fundar el hospital. Estaba emplazado en las proximidades de la Capilla de San Antonio de Padua, en Guaymallén, hacia el este del canal Zanjón, frente a la actual calle San Luis. Después del terremoto de 1861 funcionó en dos sedes provisorias hasta que se construyó el nuevo edificio en la manzana que había sido del Colegio de la Santísima Trinidad (delimitada por las actuales Santa Fe, José F. Moreno, Tucumán y Montecaseros), donde funcionó hasta su cierre definitivo a mediados del siglo xx. Los servicios que brindaba el Hospital de San Antonio fueron desde entonces proporcionados por los grandes nuevos hospitales: el Hospital Provincial (1907), el Hospital Lencinas (1924) y el Hospital Central (inaugurado en 1945).

25 El primer hospital moderno fue el Hospital Provincial construido dentro de los límites del Parque General San Martín y fruto del plan de saneamiento planteado a partir del informe Coni. En 1930 el hospital recibió un nuevo nombre, "Emilio Civit", por haber sido inaugurado durante la gestión del ex gobernador de Mendoza. Fue por muchas décadas el principal establecimiento sanitario que funcionó como maternidad, hospital general y hospital de niños.

26 Para ampliar información consultar: Luis y Aguerregaray, "De 'culpables' a 'víctimas"”, op. cit.

27 Richard Jorba, Rodolfo, "Los gobiernos radicales de los Lencinas", op. cit.

28 Las epidemias más importantes que padeció la provincia durante ese tiempo fueron la gripe (brote más fuerte 1918-1919) y la tuberculosis (que en 1922 generó la mayor cantidad de muertos por esa causa). Asimismo, en 1926 hubo un brote de escarlatina que afectó en gran medida a la población infantil. Cfr. Luis y Aguerregary, op. cit. 
Néstor Lencinas. Éste fue inaugurado en 1924. Álvarez intervino también en la terminación del proyecto y la construcción del Hospital Regional de San Rafael, inaugurado también en 1924.

Al mismo tiempo, a partir de los avances médico-científicos, en la época se entendió como fundamental la realización de análisis clínicos para la detección y control de las enfermedades. Así en 1922 se comenzaron a realizar análisis en el Hospital Provincial, y en noviembre de 1923 se inauguró el Instituto Pasteur, de bacteriología y laboratorio de anatomía patológica, que funcionó en uno de los chalets del Parque General San Martín.

En 1907 Mendoza contaba con 700 camas, y 20 años después había 1250. No obstante, en la Capital provincial no fue aumentada la capacidad hospitalaria ${ }^{29}$ en ese período, debido a que la implementación de obras públicas sanitarias estuvo dirigida a la descentralización geográfica. Para 1927 los principales hospitales de la provincia contaban con laboratorio, sala de Rayos $\mathrm{X}$ y sala de operaciones. Además, siete de los dieciocho departamentos ya tenían salas de primeros auxilios, tales eran: San Carlos, Tunuyán, Tupungato, Malargüe, Santa Rosa, Lavalle y La Paz. ${ }^{30}$

Específicamente en relación con la atención de neonatos e infantes, con anterioridad a las gestiones lencinistas los principales hospitales contaban con atención a niños, como el Hospital Provincial y el San Antonio (ambos en Capital). Además, existía "la gota de leche" por la cual se proporcionaba atención a los recién nacidos y a sus madres. Ahora bien, en julio de 1924 el Estado Provincial avanzó más y creó en la Capital la "Cantina Maternal y el dispensario de lactantes", que fueron inaugurados el 4 de agosto de 1924 (Ilustraciones 2 y 3). Éstos se ocuparon de dar apoyo alimentario a las madres necesitadas, controlando la evolución de los lactantes y transmitiendo la enseñanza de pautas de higiene personal, y normas sobre manipulación y preparación de alimentos.

Es importante señalar que en 1927 la Dirección de Salubridad estaba encabezada por el doctor Juan Antonio Orfila, un destacado médico ${ }^{31}$ que era

29 Si bien se había fundado el Hospital Lencinas, éste se dedicaba principalmente a enfermedades del pulmón e infectocontagiosas en general.

Orfila, Memoria correspondiente al año 1927, p. 8.

Juan Antonio Orfila fue un médico radiólogo que tuvo mucha incidencia en las políticas de salud provinciales, estuvo a cargo del primer Servicio de Radiología de la provincia, encabezó la Dirección de Salubridad de Mendoza y propuso un plan de reformas sanitaras entre las que destaca la reforma de la ley sanitaria de 1927 (926), que regula el ejercicio de las actividades curativas. Además, años después, en 1945 Orfila fue elegido primer director del recientemente inaugurado Hospital Central de Mendoza. Luego fue decano de la Facultad de Ciencias Médicas de la Universidad Nacional de Cuyo. Por otro lado, el médico publicó artículos científicos entre los que destaca: "Procedimiento de selección de alumnos que ingresan a la carrera médica" (1964). 


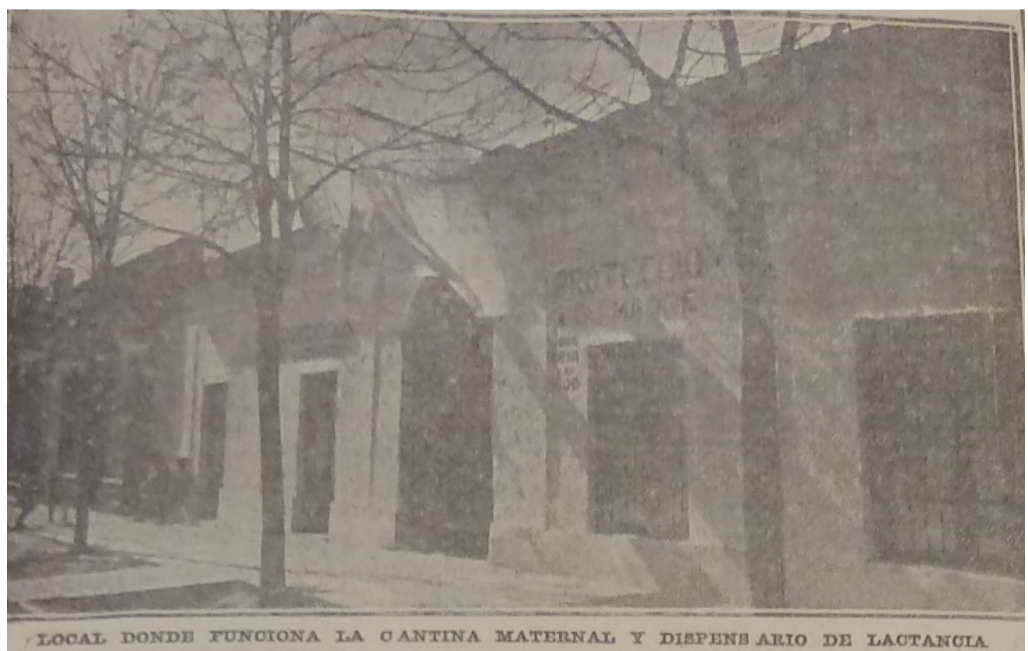

Ilustración 2. Cantina maternal y dispensario de lactantes en Capital, Mendoza. Fuente: Los Andes, 5 de agosto de 1924.

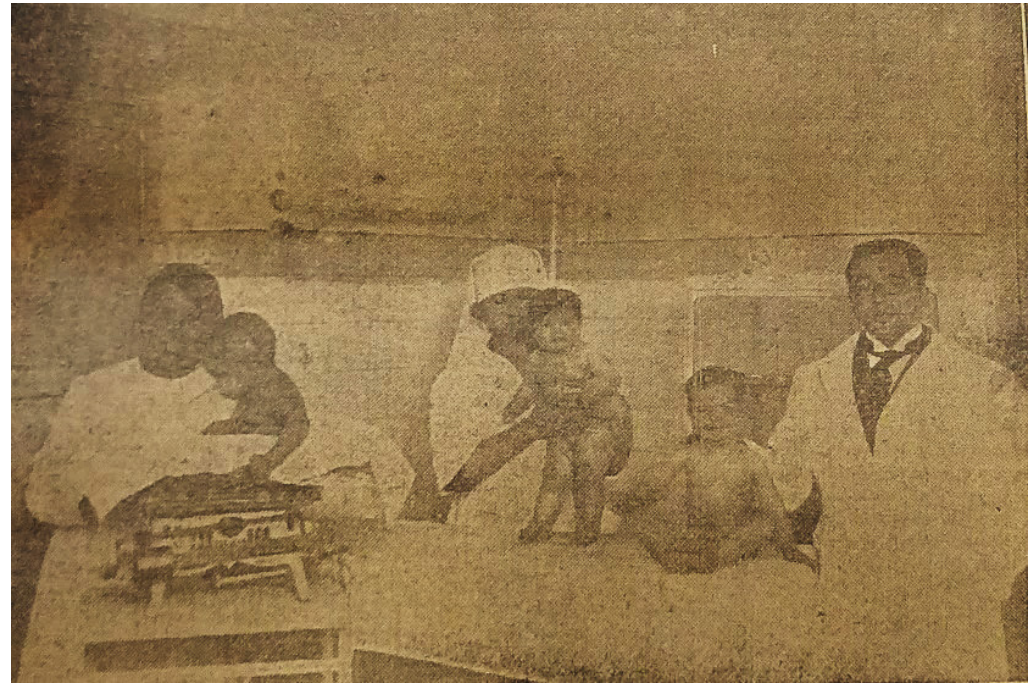

Ilustración 3. Niños atendidos en Cantina Maternal y dispensario de lactantes. Fuente: Los Andes, 5 de agosto de 1924. 
hermano de Alejandro Orfila, el último gobernador lencinista electo (19261928). Durante la gestión de Juan Antonio se proyectó un plan de mejoras sanitarias y se impulsó especialmente la atención pediátrica.

Los infantes eran atendidos en esa época en la "cantina maternal y dispensario de lactantes", ${ }^{32}$ y en los distintos hospitales de la provincia. Además, la Dirección de Salubridad había implementado la inspección de las nodrizas, y había visitadoras que examinaban en los domicilios particulares que los niños estuvieran saludables y bien alimentados. En 1927 fueron atendidos 11479 niños y la cantina maternal proporcionó a 161 madres leche de vaca para sus hijos. ${ }^{33}$

Como parte de las políticas de salud para menores, se propuso crear en 1927 un nuevo "dispensario y laboratorio de leche en la ciudad de Mendoza" (proyecto de ley elevado a la legislatura en julio de ese año). Éste otorgaría a las madres carenciadas el alimento para sus hijos basado en leche de vaca controlada y modificada, tal como se efectuaba en el Hospital de niños de Buenos Aires (inaugurado en 1875), ${ }^{34}$ con la cooperación del laboratorio de modificación de leche del Ministerio de Agricultura de la Nación..$^{35}$ Con esto se pretendía garantizar a los infantes el alimento adecuado y disminuir la mortalidad de menores debida, entre otras cosas, al consumo de leche de mala calidad o mal conservada. A diferencia del dispensario que ya estaba

32 Como personal técnico, la cantina contaba con: un director, un médico jefe del dispensario, un médico de consultorio y una partera. Entre el personal administrativo había: una ecónoma administradora, una enfermera visitadora, una preparadora de alimentos, ayudanta de esta, encargada de puericultura, enfermera mayor, enfermera menor, encargada del servicio de inspección de nodrizas y cuatro personas de servicio. Cfr. Orfila, op.cit., pp.187-188.

33 Además, hubo 1827 consultas obstétricas, 822 mujeres atendidas en la sala de Puericultura y 42 niños atendidos en la sala-cuna. Ibíd. Cfr. Orfila, op. cit.

34 El Primer Hospital de niños de Argentina se edificó en la ciudad de Buenos Aires. Éste se llamó "San Luis Gonzaga" (hoy Hospital Ricardo Gutiérrez) y fue una iniciativa de las damas de la Sociedad de Beneficencia. Fue inaugurado el 30 de abril de 1875 y se ubicó en la calle Victoria 1179 (hoy Hipólito Yrigoyen 3420). Al año siguiente se trasladó a un espacio más amplio en calle Arenales 1462. Finalmente, entre 1893 y 1896 se construyó el nuevo edificio en la calle Gallo 984/1016. En 1892 se inauguró el primer hospital pediátrico en Córdoba, el "Hospital de Niños de la Santísima Trinidad", a iniciativa de un reconocido médico que trasmitió su inquietud a la sociedad de Beneficencia. Para ampliar información consultar: http:/guti.gob.ar/quienes-somos.html

35 En Buenos Aires a fines de 1907 se aprobó una Ordenanza sobre la higienización de la leche el 13 de diciembre de 1907, en cuyo Art. $1^{\circ}$ reglamentaba que desde el $1^{\circ}$ de octubre de 1908 sería obligatoria la higienización de la leche para el consumo en la ciudad. Especificaba que se entendía por higienización de la leche, la que después de filtrada había sido pasteurizada o esterilizada. También establecía que los envases debían llevar impreso y en lugar visible el nombre de la fábrica donde se hubiera higienizado la leche (Art. $4^{\circ}$ ). En Mazzeo y Pollero, La mortalidad infantil en ambas márgenes del Río de la Plata. Recuperado de www.redaepa.org.ar/sitio_anterior/viii/AEPA/B20/Mazzeo\%20y\%20Pollero.pdf 
en funcionamiento, el nuevo contaría con personal técnico compuesto por facultativos de la Dirección General de Salubridad. Si bien no hay registro de la aprobación de dicha iniciativa, ${ }^{36}$ se sabe que un nuevo dispensario de leche comenzó a funcionar ese año en el Hospital Lagomaggiore, y los internados a causa de enfermedad infectocontagiosa en ese establecimiento fueron trasladados al Hospital Lencinas, ${ }^{37}$ con lo cual se deduce que allí se habría instaurado el dispensario de leche propuesto.

Las obras públicas sanitarias hicieron que fuera sensiblemente menor la cantidad total de decesos durante las gestiones lencinistas. Además, tal como analiza Richard Jorba, los fallecimientos en conventillos disminuyeron y aumentaron los ocurridos en hospitales, lo cual indica que se había ampliado la asistencia a enfermos graves. ${ }^{38}$ En 1923 murieron en total 7647 personas en Mendoza, y de ese total, 15 personas murieron en ese tipo de viviendas, 32 en la vía pública, 1392 en establecimientos benéficos (hospitales/ centros asistenciales) y 6183 en casas particulares. Al año siguiente el número de muertos en conventillos se redujo a nueve. ${ }^{39}$

Este fenómeno pone en evidencia el proceso de profesionalización que fue adquiriendo la salud. Creció el número de personas que morían en un hospital con equipamiento adecuado y con profesionales diversos a cargo (enfermeros, médicos especialistas, cirujanos). No obstante, esto no se modificó radicalmente, sino que el incremento del índice de personas fallecidas habiendo sido hospitalizadas fue creciendo de manera paulatina. Del mismo modo, aumentó el número de nacidos en hospitales y fue disminuyendo el porcentaje de partos en las casas particulares.

Por otro lado, más allá del lugar del fallecimiento, hubo un incremento de la cantidad de personas que morían habiendo sido asistidas. Este porcentaje da cuenta de la cobertura médico-sanitaria en todo el territorio provincial. Se puede mencionar a modo de ejemplo el departamento de Tunuyán, que pasó de tener $79.7 \%$ de personas asistidas antes de morir en 1923 , a un total del $100 \%$ en 1926, según los anuarios estadísticos publicados. ${ }^{40}$ En este caso concreto, la legislatura provincial había aprobado a fines de 1923 un proyecto de ley para invertir dinero en la ampliación y sostenimiento de la sala de primeros auxilios de dicho lugar, ${ }^{41}$ hecho que denota cómo la ejecución de obras públicas trajo

36 Recordemos que en 1927 prácticamente no sesionó la legislatura provincial, debido a la escasez de quórum producida por el obstruccionismo parlamentario de la oposición.

Los Andes, La memoria del siglo, p. 530.

Richard Jorba, "Los gobiernos radicales de los Lencinas", p. 25.

Cfr. Anuario de la Dirección general de estadísticas correspondiente al año 1923 y Anuario de la Dirección general de estadísticas correspondiente al año 1924.

40 Cfr. Anuarios estadísticos 1923, 1914, 1925 y 1926, DGEM.

41 Diario de sesiones legislativas de la Cámara de Diputados, sesión correspondiente al día 23 de noviembre de 1923. 
aparejadas mejoras concretas en el estado sanitario de la población mendocina durante la década lencinista.

Además de las obras edilicias, las medidas preventivas (vacunación, inspecciones de salubridad) y paliativas (desinfecciones) implementadas por la Dirección General de Salubridad (Ilustración 4) generaron una clara disminución de la tasa de mortalidad en Mendoza, tanto de las muertes causadas por enfermedades infectocontagiosas como en general por las demás causas de fallecimiento. Al respecto, es representativo el gráfico posterior (Ilustración 5), que demuestra la tendencia decreciente del índice de mortalidad en el período 1918-1928.

El índice general de mortalidad del año 1918 era del 23.8 por mil habitantes. Esta cifra fue descendiendo en los años posteriores llegando a 17.2 por mil en $1928 .{ }^{42}$

Específicamente en relación con la mortalidad infantil, Richard Jorba señala que durante las gestiones lencinistas ésta disminuyó significativamente, aunque continuaron vigentes las causas de muertes por enfermedades gastrointestinales, debidas en gran parte al deficiente estado sanitario con relación a la calidad del agua de consumo humano. ${ }^{43}$ En 1923 fallecieron 3660 niños menores a cinco años, y en 1927 murieron 3625 (53\% del total de muertes). ${ }^{44}$ En este sentido, si bien durante las gestiones lencinistas se disminuyó el porcentaje de fallecimientos de menores, éste continuaba arrojando números preocupantes (Ilustración 6).

Ahora bien, el problema del elevado número de mortalidad infantil (y general) no era un problema exclusivo de la provincia ni del país. ${ }^{45}$ También en los principales países a nivel mundial, ${ }^{46}$ el número de niños muertos era alarmante. Esto se debía no sólo al deficiente estado sanitario, sino también a que aún no había un gran avance en la ciencia médica (no se habían descubierto ciertos antibióticos para combatir las enfermedades, ni muchas de las vacunas utilizadas como prevención). valores por debajo de 90 por mil. En Un segundo momento (1905-1925) hubo un incremento inicial y estancamiento con tasas algo superiores al 100 por mil. Cfr. Mazzeo y Pollero, op. cit., p. 3.

46 España, por ejemplo, tenía un 172.6 por mil en 1906. Cfr. Sanz Gimeno, "Infancia, mortalidad y causas de muerte en España, 35. Recuperado de http://ih-vm-cisreis.c.mad.interhost.com/ REIS/PDF/REIS_095_07.pdf 


\section{MEDIDAS IMPLEMENTADAS POR LA DIRECCIÓN GENERAL DE SALUBRIDAD}

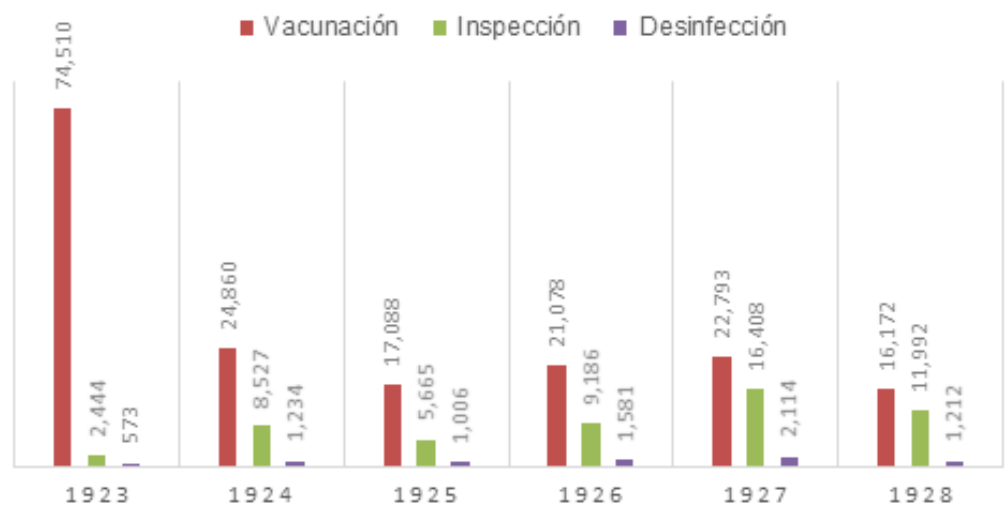

Ilustración 4. Medidas implementadas por la Dirección General de Salubridad 1923-1928.

Fuente: elaboración propia con base en los anuarios estadísticos 19231927/1929 (DGEM).

\section{Mortalidad total en Mendoza 1918-1928}

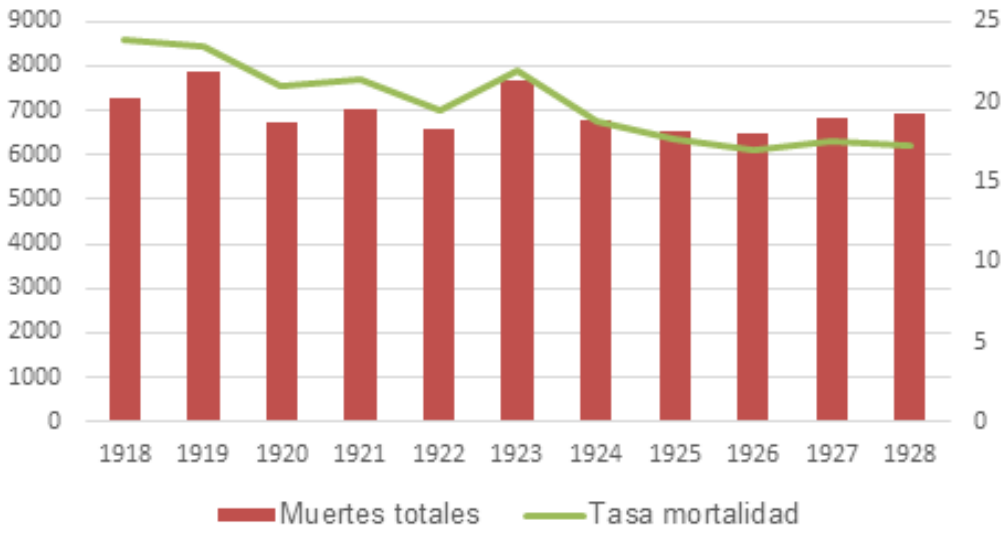

Ilustración 5. Mortalidad en Mendoza 1918-1928.

Fuente: elaboración propia con base en datos estadísticos extraídos de anuarios 1923-1927/1929 (DGEM). 


\section{Mortalidad infantil en Mendoza 1923-1929}

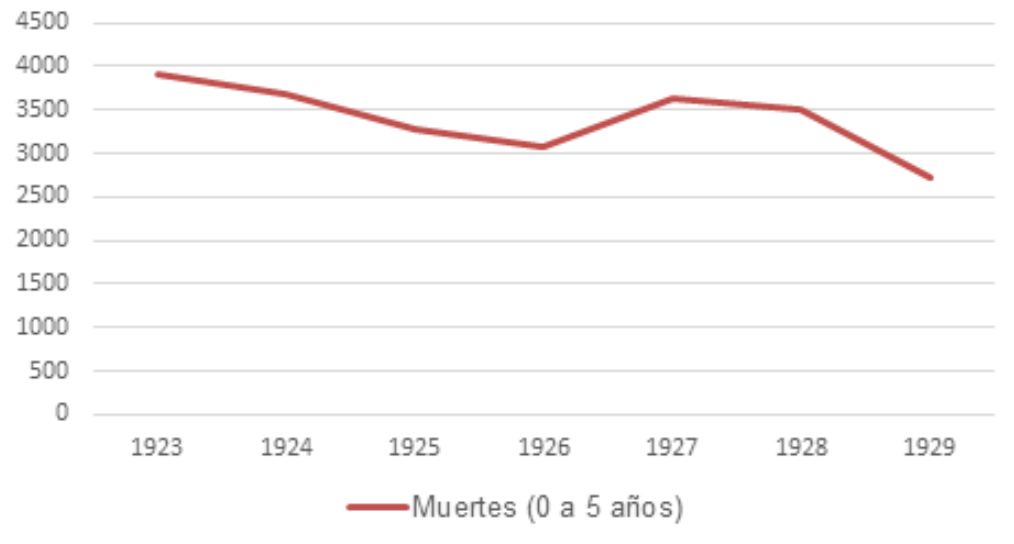

Ilustración 6. Mortalidad infantil en Mendoza.

Fuente: elaboración propia con base en datos estadísticos extraídos de anuarios 1923-1927/1929 (DGEM).

Es importante señalar que, junto al incremento de la intervención estatal en la salud pública, creció el número de profesionales. En 1927 había en Mendoza 309 profesionales con título nacional (162 médicos, 82 farmacéuticos, 26 dentistas, 7 veterinarios, 34 parteras) y 20 con título extranjero ( 8 médicos y 12 parteras). Es decir, había un médico por cada 2300 habitantes en la provincia. ${ }^{47}$ Además, en ese tiempo se asistió a la profesionalización del campo de la salud. Tanto los avances médico-científicos a nivel mundial y nacional (particularmente en microbiología), como la regulación estatal de las actividades curativas incidieron en ello. Destaca de manera particular la reforma de la ley sanitaria provincial en 1927 (Ley 926) mediante la cual

Datos extraídos de Orfila, op. cit. Años después, en 1930, se contabilizó en el país un número total de 6500 médicos. Éstos estaban concentrados en las grandes ciudades, por ejemplo, según los datos encontrados en 1935, Buenos Aires tenía un médico por cada 600 habitantes, Santa Fe cada 1 800, La Rioja cada 9 000, y Formosa tenía un médico cada 15000 habitantes. Cfr. Belmartino, Bloch, Persello y Carnino, Corporación médica y poder en salud. Recuperado de https://iris.paho.org/handle/10665.2/18746?locale-attribute=pt La cantidad de profesionales está íntimamente relacionada a la existencia o no de una facultad de ciencias médicas en el territorio. La Facultad de Medicina en Buenos Aires fue fundada en 1822 y los primeros médicos se graduaron en 1827; Mendoza recién contó con la misma en la segunda mitad del siglo xx, se inauguró en 1965. 
se le otorgó más atribuciones a la Dirección de Salubridad ${ }^{48}$ y se reguló el ejercicio de la medicina, farmacia y obstetricia. Esta normativa también fue parte del plan de mejoras sanitarias propuestos por Orfila en 1927. Por un lado, la ley estipulaba que desde ese momento sólo podrían ejercer la profesión las personas que tuvieran título profesional expedido por universidad nacional, o título extranjero revalidado (en la legislación anterior se preveía que en algunos casos la Dirección de Salubridad podría elegir "idóneos" sin título habilitante). En ese punto la normativa era entendida como una "guerra al curanderismo". ${ }^{49}$ Además, se preveía la realización de concursos para ocupar los puestos técnicos de hospitales y Asistencia Pública (artículo 73), así, se transparentaba la elección de cargos de salud, priorizando la selección de los más capacitados. De esa manera, el Estado priorizaba el "saber" en un contexto mayor signado por la ampliación de las funciones del Estado en materia social, la profesionalización del saber médico, y en el marco del incremento de la regulación de las actividades curativas.

\section{El proyecto de Hospital PEdiátrico, 1927}

Como antecedentes de establecimientos dedicados a infantes en Argentina se puede mencionar el primer hospital de niños, edificado en la ciudad de Buenos Aires. Éste se llamó "San Luis Gonzaga" (hoy Hospital Ricardo Gutiérrez) y fue una iniciativa de las damas de la Sociedad de Beneficencia. Fue inaugurado el 30 de abril de 1875 y se ubicó en la calle Victoria 1179 (hoy Hipólito Irigoyen 3420). ${ }^{50}$ Años después, en 1892 se inauguró el primer hospital pediátrico en Córdoba, el "Hospital de Niños de la Santísima Trinidad", a iniciativa de un reconocido médico que trasmitió su inquietud a la sociedad de Beneficencia. ${ }^{51}$ En 1899 se inauguró el "Hospital del niño Jesús" ${ }^{52}$ en la provincia de Tucumán. ${ }^{53}$

48 La nueva ley sanitaria agregaba funciones a la Dirección General de Salubridad, "la profilaxis y dispensarios antivenéreos, de protección a la primera infancia y dispensarios de puericultura, profilaxis de la tuberculosis, y dispensarios antituberculosos, asistencia maternal a domicilio, escuelas de enfermeros y masajistas, la inspección de casas de prostitución y la reglamentación de la lactancia mercenaria, desinfección de vehículos e higienización de la leche. Cfr. Artículo 2, Ley Sanitaria 1927. En Diario de sesiones legislativas de la Cámara de Diputados, sesión correspondiente al día 26 de enero de 1927.

49 Diario Los Andes, "La reforma de la ley sanitaria", 21 de diciembre de 1926, s/p.

50 Al año siguiente se trasladó a un espacio más amplio en calle Arenales 1462. Finalmente, entre 1893 y 1896 se construyó el nuevo edificio en la calle Gallo 984/1016.

51 Para ampliar información consultar: http://guti.gob.ar/quienes-somos/historia.html. https://www.hospitaldeninos.com.ar/hn/index.php/4-breve-historia-del-hospital.

52 Para ampliar información consultar: www.tucumanalas7.com.ar/local/2017/5/27/hospitalninos-tucuman-cumple-anos-159795.html

53 En Santa Fe el primer hospital municipal de niños fue inaugurado en 1930, por iniciativa del intendente Víctor J. Vilela. 
En Mendoza, el proyecto de construcción de un hospital pediátrico formó parte del proyecto general de los gobiernos lencinistas de mejorar la infraestructura sanitaria de la provincia, tanto a nivel de servicios de agua potable y red cloacal, como en relación con la asistencia médica. El proyecto, específicamente fue parte del plan general de reorganización sanitaria planteado por la Dirección General de Salubridad en 1927, encabezada, como se expuso, por el doctor Juan Antonio Orfila. Por un lado, esta pretendía reorganizar y equipar mejor los Hospitales y centros asistenciales existentes, y por otro, proyectaba construir nuevos establecimientos, entre los que se encontraba un nuevo local para la Asistencia Pública proyectado por el ingeniero Segismundo Klot, que se pretendía construir en 1928 sobre calle Mitre N. ${ }^{\circ} 850$ de Capital. Éste no se edificó, pero sí se utilizó un nuevo local para dicha institución en 1927, situado en calle San Martín y General Paz de Capital e inaugurado en mayo de ese año, ${ }^{54}$ y el "Hospital de Niños", ${ }^{55}$ que no logró concretarse, tal como se desarrolla a continuación.

Tanto la alta tasa de mortalidad infantil, como la necesidad de implementar políticas específicas para infantes (considerados como los más afectados) y construir un Hospital pediátrico eran divulgadas en la prensa. Los Andes aludía a la crisis sanitaria haciendo hincapié en que los más perjudicados por las enfermedades eran los niños. Señalaba: "Según nuestras diarias comprobaciones, el estado sanitario del municipio y alrededores atraviesa por un estado de intensa crisis, cuyas consecuencias pueden apreciarse por la cifra diaria de la mortalidad. Los enfermos de bronquitis y neumonía han indudablemente crecido a juzgar por la tarea de los facultativos y por la mortalidad que acusa en todos los barrios no escasas víctimas correspondiendo a los tiernos párvulos y niños el porcentaje más elevado". ${ }^{56}$

Años después, la prensa aludía: "Infinitos ejemplos permiten demostrar que la excesiva mortalidad infantil, por demás alarmante en esta provincia, deben combatirse por todos los medios al alcance de las autoridades y del público, y que ambos son responsables de ese mal cuyas fatales consecuencias no solo importan un atraso sino también un desastre para el desarrollo normal de la población". ${ }^{57}$

Si bien existía la cantina maternal, y los menores recibían atención pediátrica en los principales centros asistenciales de la provincia, no había aún un hospital pediátrico. En este sentido, la Dirección de Salubridad propuso su construcción como parte esencial del plan de reformas y mejoras sanitarias para Mendoza.

55 Cfr. Orfila, Juan Antonio, op. cit., p. 115.

56 Diario Los Andes, 7 de agosto de 1916, s/p.

57 Diario Los Andes, 3 de noviembre de 1927, s/p. 
Es importante señalar que las condiciones de vida de los infantes en ese tiempo (y también hoy en día) dependían directamente de la ubicación en la escala socioeconómica donde se ubicaba el niño. Es decir, existía gran diferencia entre la calidad de vida y salud de un niño de la élite, y la de un niño hijo de un trabajador pobre. La mala alimentación y el nulo o escaso cuidado de las embarazadas incidían directamente en la salud del neonato. Asimismo, influía en la salud de los infantes el trabajo infantil, la alimentación y la escasez de cuidados generales. Por ello, las soluciones estaban ligadas a programas educativos de las mujeres (como el Instituto de Puericultura) y a plantear programas de profilaxis desde las políticas públicas.

\section{RAÚL ÁLVAREZ: SU TRAYECTORIA COMO FUNCIONARIO “TÉCNICO" DEL ESTADO}

Raúl Jacinto Álvarez ${ }^{58}$ fue un arquitecto que desempeñó una labor importante desde la función pública en los gobiernos lencinistas, en el marco del desarrollo de la profesión en el país.

En Argentina, el programa modernizador (fines XIX/Xx) dejó formulada la oposición entre las profesiones "liberales" y las "comerciales". La abogacía, la medicina y la ingeniería fueron las profesiones liberales por antonomasia; tuvieron un papel central estructurante en la formación y reproducción de la clase dirigente argentina y en el proceso de constitución del estado moderno. La arquitectura, desprendida funcionalmente de la ingeniería, quedó sometida a las mismas condiciones articulatorias con el desarrollo social que sostenía esta disciplina. El desarrollo de las profesiones liberales estuvo ligado a la creación y consolidación de las universidades que apuntaron a cubrir las necesidades básicas de la administración de un país extenso con un vertiginoso crecimiento, donde era perentorio cubrir los puestos de un gran aparato burocrático, técnico y especializado que respaldase el desarrollo de las actividades productivas, administrativas, de servicio y comerciales.

El ejercicio liberal de la profesión era el eje medular de la vida laboral de los arquitectos y el estudio era el ámbito "natural" de desarrollo de las tareas. El arquitecto se ubicaba como "director de orquesta" en la ejecución de su obra, de la cual era a la vez compositor y artista. En el quehacer diario de los profesionales arquitectos había mucho tiempo dedicado a las relaciones y la vida social. Estaba pautado en el imaginario del grupo que las posibilidades

58 Para ampliar información sobre la biografía de Álvarez consultar: Cfr. Berná Vaccarino, Obra pública del arquitecto Raúl Álvarez en Mendoza. Recuperado de https://bdigital.uncu. edu.ar/4594; y Cirvini, “Álvarez, Raúl Jacinto”. Recuperado de http://bdigital.uncu.edu. ar/9327. 
de conseguir encargos "importantes", dependía en gran medida de las vinculaciones sociales y los contactos que podían realizarse, en los diferentes ámbitos donde se movían los grupos de la élite. Conferencias, almuerzos, cenas, reuniones sociales de distinto tipo, eran espacios compartidos con potenciales comitentes. Este cultivo de los vínculos sociales era tan importante que es posible identificar, en distintas trayectorias, los ámbitos de relación en los que se movían los practicantes, por el origen de los encargos profesionales.

En este marco, puede comprenderse la labor del arquitecto Álvarez en Mendoza. Perteneciente a una tradicional familia de la élite mendocina, ligado a la clase política y en particular al radicalismo, y con vínculos con la comunidad de inmigrantes españoles prósperos como los Arizu, tuvo la oportunidad de desarrollar una importante obra pública, con apenas un año de egresado de arquitecto y también de ganarse con el tiempo, una clientela entre la élite que valoraba el plus diferencial de contratar a un profesional para sus casas, sus edificios de renta y sus bodegas.

Raúl Jacinto nació en Mendoza en 1890. Cursó sus estudios en Buenos Aires, ciudad donde residió la mayor parte de su vida. Fue hijo del escritor, historiador y político mendocino Agustín Álvarez. ${ }^{59}$ Obtuvo el título de Arquitecto en la Escuela de Arquitectura de la Facultad de Ciencias Exactas, Universidad de Buenos Aires, el 20 de enero de 1917, convirtiéndose así en el primer mendocino que se graduó de arquitecto. Fue presidente del Centro de Estudiantes y parte del grupo fundador de la Revista de Arquitectura, publicación señera de la corporación de arquitectos y a la cual estuvo ligado como colaborador o editor durante toda su vida. Fue un activo estudiante ligado al ideario arielista y al movimiento de la Restauración nacionalista, liderado por Ricardo Rojas y Leopoldo Lugones.

Trabajó en todos los ámbitos posibles: el estudio de arquitectura, la función pública, la docencia y las organizaciones profesionales. En Buenos Aires estuvo asociado con el arquitecto Raúl R. Rivera, con quien realizó en 1918 el proyecto que mereció el primer premio del Concurso de Planimetrías y Tipos de Casas adoptadas por la Comisión Nacional de Casas Baratas. Ocupó en Mendoza, bajo la administración de José N. Lencinas, el cargo de jefe de la Sección Arquitectura e, interinamente, el de Director de Obras Públicas de la Provincia. En 1918, proyectó importantes reformas a la Legislatura de la Provincia dotando al edificio del recinto de sesiones, obra que se llevaría a cabo

59 Agustín Álvarez nació en Mendoza en 1857. Se recibió de abogado y fue escritor, político y docente destacado. Entre sus principales obras se encuentran: "Manual de patología política" (1899), "Ensayo sobre Educación”(1901), “'Adónde vamos?”(1902), "La transformación de las razas de América" (1908), "Historia de las Instituciones libres" (1909), "Breve Historia de la Provincia de Mendoza" (1910), "La herencia moral de los pueblos hispanoamericanos" (1919). En 1892 fue electo diputado nacional y se trasladó a la ciudad de Buenos Aires. Murió en Mar del Plata en 1914. Cfr. Berná Vaccarino, op. cit. 
recién en 1923. También en 1919 realizó la "Rosaleda" del Parque General San Martín. Ganó por concurso el proyecto del "Hospital Español" de Mendoza en 1923; realizó los proyectos de las jefaturas políticas de Godoy Cruz (luego sede de la policía provincial) y la de la villa de San Carlos en el valle de Uco, el Hospital de infecciosos Lencinas y entre otras, la Escuela Bombal. Participó en el "Concurso de Anteproyectos para el Palacio de Gobierno de Mendoza" obteniendo el 2o. premio en 1927. Proyectó también numerosas viviendas urbanas y rurales. Tuvo numerosos encargos de la familia Arizu para quienes realizó numerosas obras en sus bodegas de Godoy Cruz y Villa Atuel en el sur mendocino, sus chalets y residencias urbanas. Fue profesor en la Escuela de Arquitectura de la Universidad de Buenos Aires (UBA).

Álvarez fue un ferviente defensor del sistema de concursos y un asiduo participante de congresos nacionales e internacionales de la disciplina arquitectónica. En Mendoza, y con su mediación, en 1926 se convocó a concurso nacional para la construcción de la nueva Casa de gobierno en el centro de la Plaza Independencia, obra que después no se realizó, ocupándose el sitio para construir un Teatro Municipal.

Con respecto a la labor de los arquitectos durante el período lencinista, es importante señalar que, si bien entre fines del siglo XIX y comienzos del Xx la labor de los profesionales (entre otros, arquitectos) en la administración pública era considerado como una salida laboral secundaria y alternativa, en la década de 1920 esto se modificó y comenzó a ser evaluada desde una perspectiva diferente, teniendo ya en cuenta, como aspecto importante, la función social de la profesión ante la aparición de nuevos problemas urbanísticos y arquitectónicos que había generado el mismo proceso modernizador. Desde entonces, y en forma creciente hasta mediados del siglo xx, el espacio laboral de la función pública fue progresivamente valorizado, como la vía adecuada a los tiempos, para acceder a nuevos logros y desafíos de la profesión, tal como el tema de la vivienda popular o los problemas urbanos (transportes, equipamiento, infraestructura). De hecho, las necesidades del proceso modernizador dentro del Estado promovieron, en las distintas jurisdicciones de la administración pública, la formación de una burocracia técnica ${ }^{60}$ cada vez más compleja y eficiente para planificar y ejecutar obras en todo el territorio nacional. ${ }^{61}$

60 Cabe destacar que en 1922 hubo un proyecto de ley que pretendía reglamentar en Mendoza el ejercicio de la arquitectura, agrimensura e ingeniería, estableciendo como obligatorio la necesidad de contratar profesionales para la ejecución de obras públicas (Ley de reglamentación profesional, 1922. En Suárez, Memoria del Ministerio de Obras públicas. Si bien la ley no se sancionó, da cuenta del debate provincial y nacional (Ley 4560 de 1905) acerca de la necesidad de reglamentar el ejercicio profesional y de realzar el papel ejercido por personal técnico en las obras públicas.

61 Para ampliar información sobre las condiciones de trabajo de los arquitectos durante el lencinismo, cfr. Cirvini, Nosotros los arquitectos. 


\section{LA ARQUITECTURA HOSPITALARIA EN LA OBRA DE RAÚL J. ÁlVAREZ}

La arquitectura hospitalaria sufrió una importante evolución a fines del siglo XIX con el desarrollo de la microbiología derivado de las teorías de Pasteur. Saber cómo se propagaban las enfermedades infecciosas permitía diseñar hospitales como dispositivos eficaces para evitar el contagio y garantizar la asepsia de áreas de cirugía. Es notable cómo cambiaron las tipologías de hospitales de la tradicional planta claustral de la época colonial a la estructura pabellonar y con la utilización de jardines como fuelles de ventilación y aislación entre los bloques.

En Mendoza, el primer hospital moderno que se construyó fue el anteriormente mencionado Hospital Provincial (luego llamado "Emilio Civit"), inaugurado en 1907 (Ilustración 7). Su planta de pabellones aislados unidos por circulaciones a cielo abierto permitió un crecimiento gradual dotándolo de más capacidad de camas. Dejó de funcionar a fines del siglo xx cuando ya todos los hospitales especializados lo reemplazaron en sus funciones.

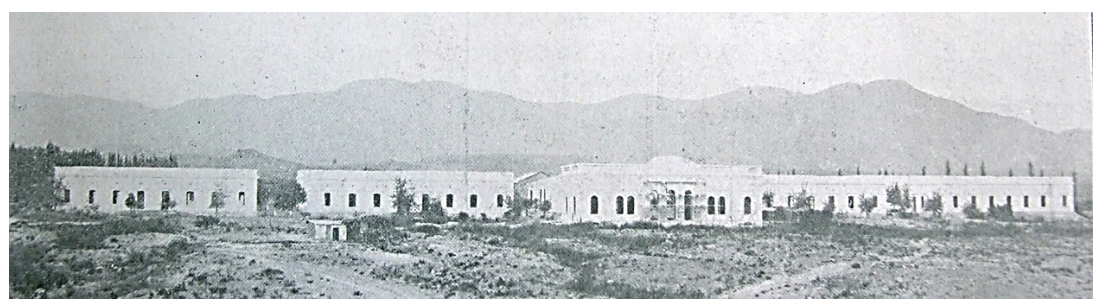

Ilustración 7. Hospital Provincial, 1907.

Fuente: Gobierno de Mendoza. Álbum Argentino Gloriandus. Provincia de Mendoza, su vida, su trabajo, su progreso, 1909.

Años después, el arquitecto Raúl J. Álvarez realizó en Mendoza importantes obras de arquitectura hospitalaria: en 1919 realizó, como se expuso al comienzo, el proyecto del Hospital para infecciosos José Néstor Lencinas (Ilustración 8), construido para hacer frente a las enfermedades infecciosas, especialmente la tuberculosis. Para su ubicación se eligió un terreno forestado perteneciente al parque General San Martín en el extremo sur (cuando aún no se había seccionado el paseo entre los departamentos de Capital y Godoy Cruz). Sobre un esquema funcional de pabellones inmersos en un extendido jardín el edificio se construyó con la mejor tecnología de la época y en un estilo neocolonial simplificado. Se destinaron dos pabellones a los afectados del pulmón de ambos sexos y uno a niños atacados de tuberculosis ósea, además 


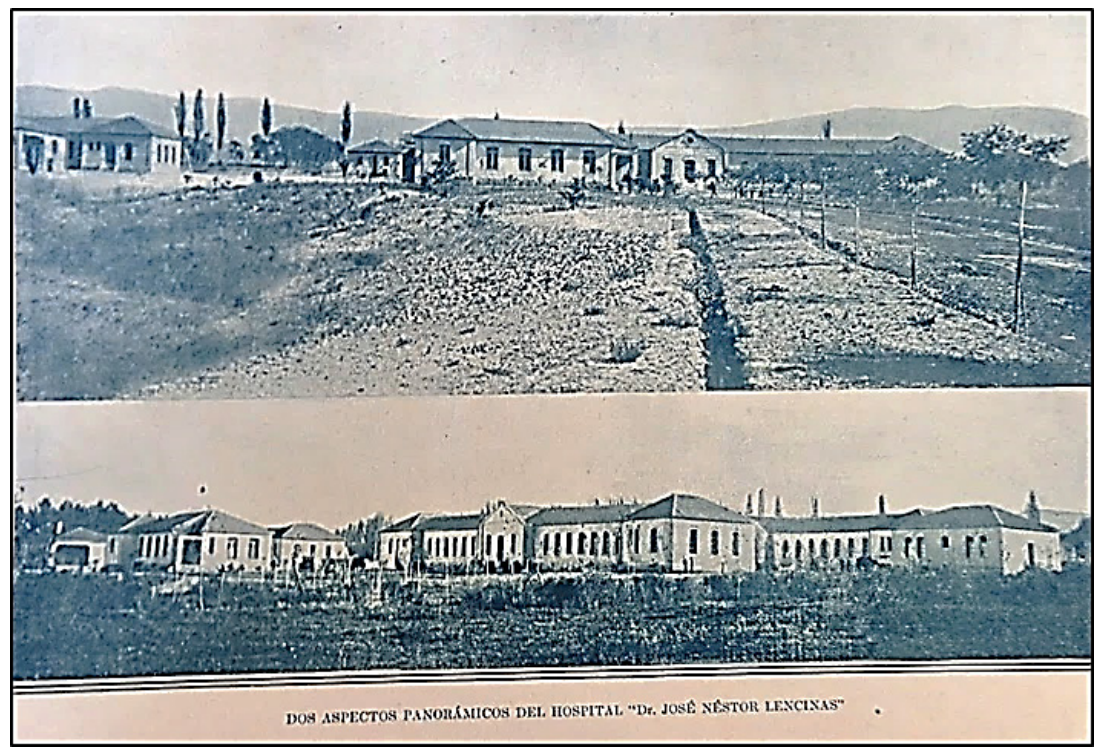

Ilustración 8. Hospital José Néstor Lencinas, 1924.

Fuente: Suárez, Leopoldo, Memoria presentada a la honorable legislatura por el ministro de Industrias y Obras Públicas, año 19221923, (Mendoza, 1924).

de poseer un solarium para su tratamiento. Asimismo, se contó con otro pabellón destinado al resto de las enfermedades infectocontagiosas, en donde los dolientes se encontraban totalmente divididos y aislados. Fue inaugurado en 1924.

También en 1919 Raúl Álvarez intervino en la terminación del proyecto y la construcción del Hospital Regional de San Rafael, luego llamado Dr. Schestakow (Ilustración 9), obra iniciada en 1905 y que había quedado paralizada por años. El gobernador Lencinas decidió reanudar la obra bajo la supervisión de la Dirección General de Obras Públicas de la Provincia, según un plan general elaborado por la Sección Arquitectura, a cargo en ese momento de Álvarez. Si bien el plan general había sido elaborado en 1905 por una comisión de médicos entre los que estaba Schestakow, es evidente, a partir de las similitudes que presenta con el hospital Lencinas que fue Álvarez quien le otorgó la fisonomía final al edificio, sus terminaciones y las características de ese estilo sobrio que combinaba pintoresquismo con neocolonial. ${ }^{62}$ 


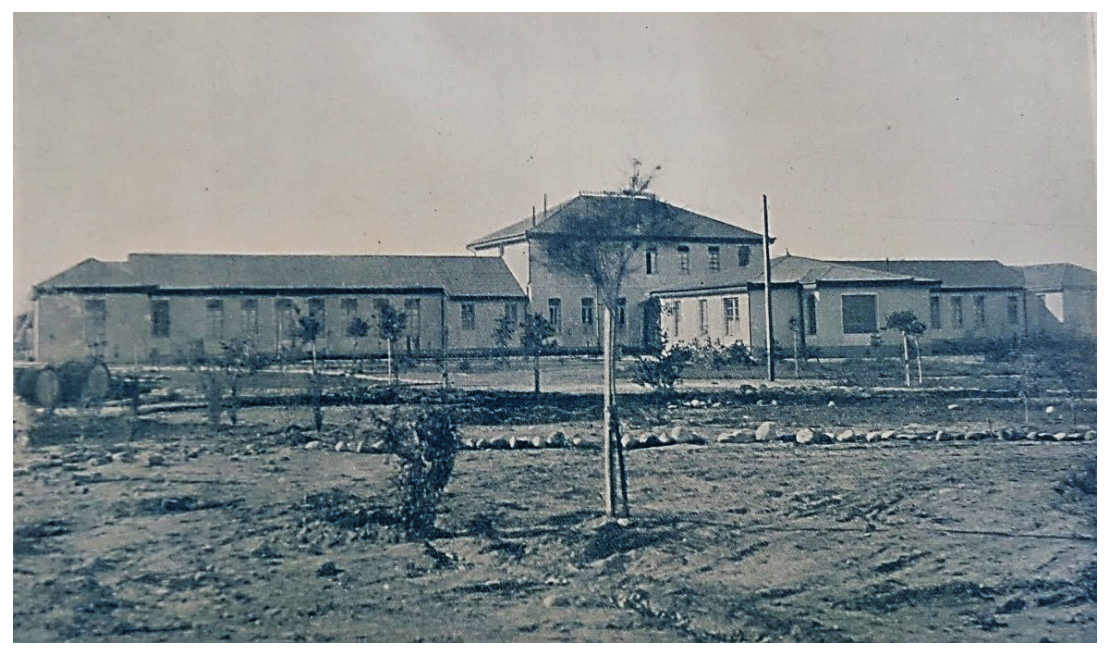

Ilustración 9. Hospital Regional de San Rafael, 1924.

Fuente: Suárez, Leopoldo, Memoria presentada a la honorable legislatura por el ministro de Industrias y Obras Públicas, año 19221923 (Mendoza, 1924).

En 1923, Álvarez ganó un concurso privado del proyecto del Hospital Español de Mendoza, obra pionera no sólo del equipamiento hospitalario de instituciones privadas, en este caso la colectividad española, sino del estilo neocolonial en su versión más ortodoxa: columnas salomónicas, frontis barrocos, colores blanco y ocre en los muros, pisos rojos con alhambrillas, fuentes y patios españoles, entre otros.

\section{El PROYECTO DE Hospital de NiÑos}

En 1927, el arquitecto Álvarez realizó el proyecto del primer hospital de niños de Mendoza (Ilustraciones 10 y 11). Los planos publicados en una memoria de la Dirección General de Salubridad no indican la ubicación precisa, la cual no se ha podido determinar. Se trata de una manzana completa y comprende siete pabellones de los cuales los dos frontales son de "Administración y consultorios externos" y el "Instituto de Puericultura". Este último establecimiento tiene gran importancia en el conjunto y se propone como una institución pionera en el país para el tratamiento de la salud en la primera infancia. Luego posee dos pabellones destinados a la internación: uno para enfermos de clínica general y otro para cirugía, que suman ambos 100 camas. También cuenta con un pabellón destinado a albergar tres quirófanos con todos los locales de apoyo, 


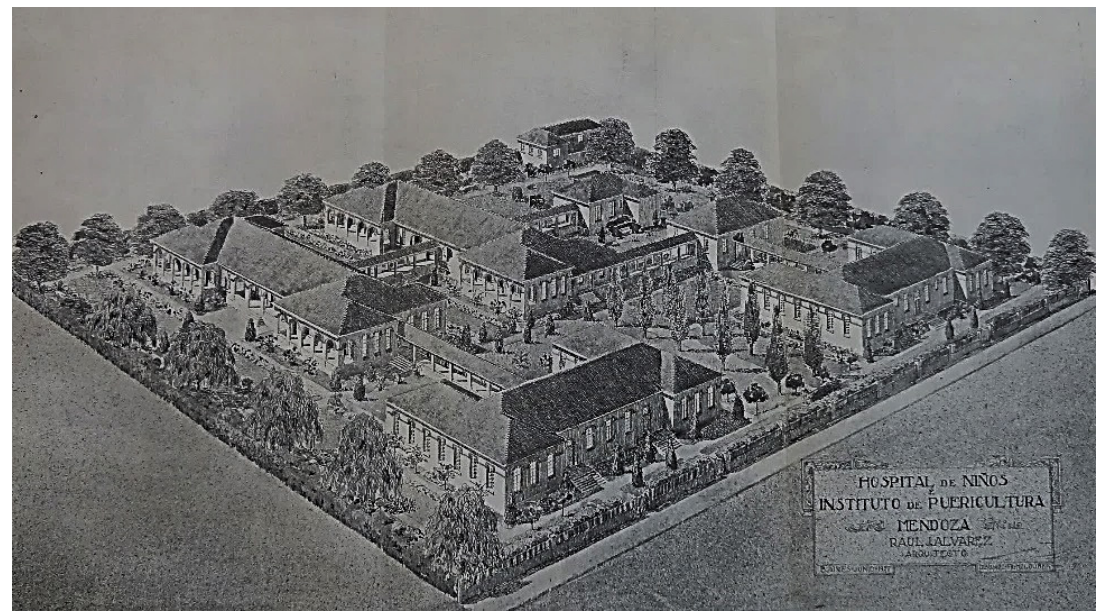

Ilustración 10. Proyecto Hospital de niños, 1927.

Fuente: Orfila, Antonio, Memoria de la Dirección de Salubridad correspondiente a 1927 (Mendoza, 1928).

que se une a través de galerías cubiertas con los pabellones de internación. Finalmente, el conjunto posee dos pabellones de servicios, uno de cocina que se une con los pabellones de internación a través de galerías cubiertas y otro pabellón aislado de lavado, planchado, desinfección y morgue. Los hospitales diseñados por Álvarez, como muchos de la época, se adecuaban a los lineamientos de las autoridades de Salubridad, acordes a los avances de la biología, la bacteriología y la medicina. El esquema pabellonar ${ }^{63}$ se impuso por cuanto respondía a la condición de aislar funciones y usos diferentes, evitando contagios en el caso de las infecciones y permitiendo mantener la asepsia en áreas quirúrgicas.

El estilo empleado era muy similar al de los hospitales Schestakow (San Rafael) y Lencinas (Mendoza Capital) y la Escuela Bombal, techos inclinados de chapa pintada, carpinterías moduladas de perfiles metálicos, muros lisos y con escasa ornamentación enmarcando accesos y aberturas. Los jardines unían todo el conjunto y permiten no sólo la correcta aireación e iluminación de los locales de cada pabellón sino actuar como un espacio necesario y saludable, indispensable en la sanación de los enfermos.

Toda la obra hospitalaria y escolar de Álvarez portaba las marcas de la arquitectura pública del período: las plantas eran funcionales, sobre planteos

63 Los pabellones son unidades aisladas, rodeadas por lo general de espacio abierto forestado, unidos por circulaciones horizontales. 


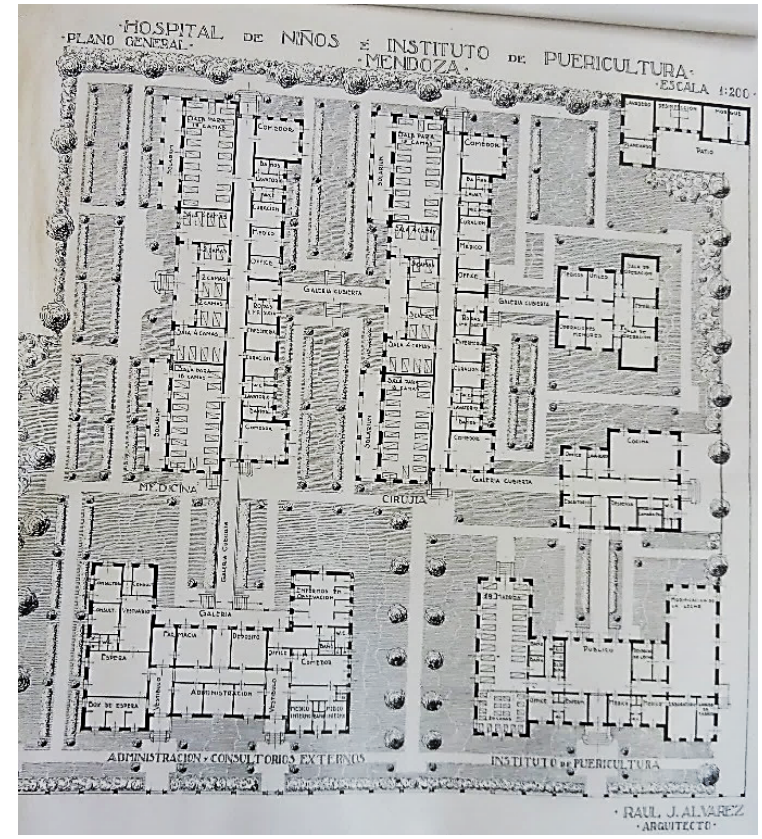

Ilustración 11. Plano de arquitectura del Hospital de niños, 1927.

Fuente: Orfila, Antonio. Memoria de la Dirección de Salubridad correspondiente a 1927 (Mendoza, 1928).

de avanzada para la época en materia de salud y educación, materiales nuevos con sistemas de vanguardia, mientras que los lenguajes formales buscaban un sello propio de lo que se había denominado "arquitectura nacional", inspirada en modelos del pasado colonial y alejada de los academicismos.

Es importante señalar en este punto que la arquitectura pública de las primeras décadas del siglo xx en Argentina ensayó nuevas tecnologías y materiales de vanguardia, particularmente se alude al uso del hormigón armado. Los factores específicos que contribuyeron al desarrollo de esta vanguardia en la región y en especial en Mendoza fueron varios y concurrentes. En primer lugar, el apoyo oficial y la voluntad de la clase política y la élite para hallar mejores soluciones al antiguo problema de los sismos ${ }^{64}$ constituyeron la base que facilitó la circulación y la difusión de las propuestas y convocó voluntades 
en torno de su promoción y aceptación. Otro de los factores decisivos fue el estado alcanzado por el conocimiento científico-técnico, el cual en el marco de la ingeniería moderna aspiraba a hallar soluciones universales y apelaba a su vez a las experiencias de otros países del mundo, en el afán de acumular conocimiento y avanzar en las teorías producidas. En este sentido, Argentina se ubicaba a comienzos del siglo xx en la avanzada del estudio científico y sistemático del uso del hormigón armado en el ámbito mundial, a la par de Francia, Italia y Estados Unidos de Norteamérica. El desarrollo de la tecnología del hormigón armado continuaría avanzando progresivamente durante todo el siglo xx, pero no alcanzaría difusión masiva sino hasta después de 1960. Durante las primeras tres décadas del siglo su uso estuvo restringido a edificios públicos y privados del equipamiento urbano, a viviendas urbanas y chalets suburbanos o rurales de la clase dirigente y la burguesía vitivinicultora, a piletas para depósitos de vino en "cemento armado", y obras de infraestructura: diques, puentes, caminos carreteros y obras de arte del sistema de irrigación.

La dependencia total, en los primeros años de la importación de cemento y acero fue un escollo importante que se fue superando desde 1919 hasta mediados del siglo con la producción de cementeras en el país y la instalación de la primera fábrica local en 1936, lo cual cambiaría significativamente el panorama de la construcción local al abaratar el costo. ${ }^{65}$

Puede decirse, sin lugar a duda, que Álvarez recorrió en su trayectoria los múltiples espacios que un arquitecto de la primera mitad del siglo xx podía ocupar: el ejercicio liberal de la profesión, la actividad en la administración pública y la docencia universitaria. Asimismo, adhirió a las búsquedas y debates de la época en torno a la "arquitectural nacional", apoyó el desarrollo de la práctica de los concursos de arquitectura y participó de congresos panamericanos que tomaron gran impulso desde la década de 1920. Finalmente, Álvarez encontró un espacio de actuación en las instituciones profesionales y gremiales que representaban un núcleo aglutinador de la identidad grupal de la naciente profesión: desde el Centro de Estudiantes a la Sociedad Central de Arquitectos, utilizando la prensa técnica como un medio eficaz de llegada al público y a sus colegas.

\section{EPÍLOGo}

A modo de síntesis, puede afirmarse que, como parte de las políticas de mejora sanitaria proyectadas en la provincia de Mendoza por los dirigentes lencinistas, se propuso la construcción de un hospital pediátrico. La alta tasa

65 Para ampliar información consultar: Cirvini, "La edificación "contra temblores"; y Cirvini, Silvia, Gómez Voltán, José, "El cemento armado y la construcción sismorresistente en Mendoza, Argentina". 
de mortalidad infantil, sobre todo de 0 a 5 años, puso en evidencia la necesidad de aplicar políticas precisas para mejorar la salubridad de la población infantil. Por un lado, se pensó mejorar la higiene, los controles y la alimentación de los neonatos y lactantes, y se creó la cantina maternal en 1924. Luego se avanzó más inaugurando un laboratorio y dispensario de leche materna en el Hospital Lagomaggiore en 1927. Por otro lado, se propuso construir un hospital especializado en niños, para así atender de manera integral y específica a los menores. Sin embargo, este último proyecto no se concretó. Esto se debió a varias razones, por un lado, a la parálisis legislativa provocada por el obstruccionismo parlamentario de la oposición (que generó que la legislatura prácticamente no sesionara ese año). Ello, sumado a que una nueva intervención federal ya era rumor en la prensa manifestando, una vez más, la inestabilidad política propia del período. Por último, la crisis financiera, producida no sólo por el crecimiento del gasto público sino, además, por un déficit fiscal crónico, una deuda pública impaga y la circulación de letras de tesorería ${ }^{66}$ también debe haber jugado un papel significativo a la hora de priorizar obras a ejecutar durante la última gestión lencinista.

Si bien el proyecto no logró concretarse, es un antecedente pionero del primer hospital pediátrico de Mendoza, finalmente concretado recién en 1980 y rebautizado doce años después como Humberto Notti. Es importante señalar que en la década peronista (1946-1955), entre la prolífica obra pública dedicada a atender la salud, se proyectó y comenzó a construir un Hospital de Niños en el Parque San Martín, muy cerca del Hospital Provincial. Sin embargo, este establecimiento sostenido y administrado por la Fundación Eva Perón nunca llegó a funcionar como hospital. Luego del derrocamiento de Juan D. Perón en 1955 las instalaciones se destinaron y adaptaron para el funcionamiento de la Facultad de Medicina ${ }^{67}$ de la Universidad Nacional de Cuyo, inaugurada en 1965.

Cfr. Barrio, "Finanzas públicas y vitivinicultura durante el lencinismo", op. cit.

El 26 de diciembre de 1950 se creó la Facultad de Ciencias Médicas de la UNCuyo, que abarcaría las Escuelas de Medicina, Odontología, Bioquímica, Farmacia, y las Escuelas Auxiliares de Obstetricia y Kinesiología, Servicio Social y Pedagogía Social. El plan era sumamente ambicioso y complejo, pero se dispuso de recursos escasos, de manera que sólo comenzó su actividad la Escuela de Medicina. El Ministerio de Salud Pública colaboró con las instalaciones de los Hospitales Central, Emilio Civit y Lagomaggiore, para que se desarrollaran allí las labores docentes. Se esperaba que la Facultad de Medicina y los esfuerzos por apoyar su establecimiento en Mendoza haría posible sanear la salud de la población. En 1955 comenzó a cristalizar el sueño de una sede propia para la Facultad de Medicina a través de la cesión de las todavía inconclusas construcciones destinadas al Hospital de Niños. En 1965, el estado de las obras permitió iniciar el traslado al nuevo edificio, que sería el primero de lo que conocemos como la Ciudad Universitaria. Para ampliar información consultar: http://fcm.uncuyo.edu.ar/historia 
Por otro lado, es importante destacar que los gobiernos lencinistas potenciaron y concretaron la descentralización geográfica iniciada con los gobiernos conservadores. ${ }^{68}$ Así, tanto en la mejora de las salas de Primeros Auxilios departamentales y en las propuestas de instalación de farmacias, como en los proyectos de extensión de la red de agua potable y cloacal, es posible advertir que las políticas sanitarias y de salubridad propuestas beneficiaron a sectores sociales más amplios, antes marginados, facilitando el servicio en los arrabales de la ciudad y en las zonas apartadas de la capital mendocina.

La propuesta del hospital de niños formaba parte, como se dijo, del ideario planteado por los lencinistas para mejorar la salud de la población. Esto, enmarcado en un contexto mayor en el que se entendía (ya desde fines del siglo XIX y comienzos del xx) que era el Estado el encargado de velar por la seguridad, salud y buenas condiciones habitacionales de la población. Eran entendidas como problemáticas que el Estado debía resolver a partir de planes específicos elaborados mediante el estudio y saber técnico, ${ }^{69}$ que serían plasmados en políticas públicas. La salud había dejado de ser ámbito de competencia de la caridad o beneficencia pública para pasar a ser un espacio de intervención estatal directa. ${ }^{70}$

En otro plano del análisis efectuado se puede concluir que el proyecto forma parte de la labor de Raúl Álvarez como profesional técnico principal de la obra pública lencinista. La trayectoria de este arquitecto es muy explicativa de los procesos de consolidación de la burocracia técnica del Estado y de la ampliación de los deberes y funciones de los profesionales en el ámbito de la arquitectura pública.

Es probable que la influencia recibida en el hogar paterno (con una visión filosófica crítica y una posición política democrática) más la formación de la flamante Escuela de Arquitectura hayan resultado una valiosa combinación que le dio ventajas relativas: Álvarez pudo combinar la tarea del profesional liberal con una sólida formación académica trabajando para una élite, con la labor desde la administración pública con los nuevos grandes desafíos que planteaba la sociedad de masas. Era, en varios sentidos, un arquitecto de su tiempo, riguroso en relación al diseño moderno acorde a los nuevos requerimientos sociales y técnicos de la época, preocupado por los significados simbólicos de la arquitectura en la búsqueda de una expresión estética propia y finalmente un fervoroso defensor de las estructuras corporativas y de los mecanismos propios

Cfr. Richard Jorba, op cit., 2011.

Para ampliar información consultar: Ben Plotkin, Mariano y Zimmermann, op cit.

Esto ocurrió no sólo a partir del traspaso de la administración de los centros asistenciales surgidos de la caridad pública a la órbita estatal, sino a partir del reconocimiento de que la problemática sanitaria era un asunto para resolver por el Estado. Para ampliar información consultar: Ponte, El Carmen. Hospital de la filantropía. 
de la profesión como los concursos, que permitirían satisfacer las necesidades aumentadas de un país que crecía y ampliaba su base social.

\section{FuenTES}

Anuario de la Dirección General de Estadísticas correspondiente al año 1923, Buenos Aires: Talleres S. A. Casa Jacobo Peuser, LTDA, 1924.

Anuario de la Dirección General de Estadísticas correspondiente al año 1924, Buenos Aires: Talleres S. A. Casa Jacobo Peuser, LTDA, 1926.

Anuario de la Dirección General de Estadísticas correspondiente al año 1925, Buenos Aires: Talleres S. A. Casa Jacobo Peuser, LTDA, 1926.

Anuario de la Dirección General de Estadísticas correspondiente al año 1926, Buenos Aires: Talleres S. A. Casa Jacobo Peuser, LTDA, 1928.

Anuario de la Dirección General de Estadísticas correspondiente a los años 1927-1929, Buenos Aires: Talleres S. A. Casa Jacobo Peuser, LTDA, 1931.

Ley Sanitaria $\mathrm{n}^{\circ}$ 926, 1927, en Diario de sesiones legislativas de la Cámara de Diputados, sesión correspondiente al día 26 de enero de 1927.

Orfila, Juan Antonio, Memoria correspondiente al año 1927 presentada al Ministerio de obras públicas por el director general de salubridad, Mendoza, 1928.

Suárez, Leopoldo, Memoria presentada a la honorable legislatura por el ministro de industrias y obras públicas Ingeniero Leopoldo Suárez. Año 1922-1923, Mendoza, 1924.

Notas periodísticas: Los Andes, 5 de agosto de 1924; Los Andes, "La reforma de la ley sanitaria", 21 de diciembre de 1926, s/p.; Los Andes, 7 de agosto de 1916, s/p.; Los Andes, 3 de noviembre de 1927, s/p.

Gobierno de Mendoza, Álbum Argentino Gloriandus. Provincia de Mendoza, su vida, su trabajo, su progreso, Mendoza: Ed. Oficial, 1909.

\section{Sitios ELECTRÓNICOS}

Historia del Hospital Gutiérrez. Recuperado de http:/guti.gob.ar/quienes-somos.html Historia del Hospital del Niño Jesús (Tucumán). Recuperado de www.tucumanalas7. com.ar/local/2017/5/27/hospital-ninos-tucuman-cumple-anos-159795.html

Historia de la Facultad de Medicina de la UNC, Mendoza. Recuperado de http://fcm. uncuyo.edu.ar/historia

\section{REFERENCIAS}

Aguerregaray, Rosana, Representaciones y prácticas de la muerte de la élite mendocina: proyectos disciplinadores y modalidades de secularización (18871935), (inédito), tesis de doctorado, Mendoza, Argentina: Facultad de Filosofía y Letras, Universidad Nacional de Cuyo, 2016.

, "De la higiene pública a la higiene social en Buenos Aires, una mirada a través de sus protagonistas, 1880-1914", en Boletín Mexicano de Historia y Filosofía de la Medicina, vol. 10, núm. 1, 2007, pp. 4-11. 
Álvarez Cardozo, Adriana, "La aparición del cólera en Buenos Aires (Argentina), 18651996", en Historelo, vol. 4, núm. 8, 2012, pp. 172-208.

DOI: https://doi.org/10.15446/historelo.v4n8.33608

Álvarez, Adriana (comp.). La historia de la salud y la enfermedad, Mar del Plata: EUDEM, 2018. Recuperado de http://www2.mdp.edu.ar/images/eudem/pdf/ la_historia_de_la_salud_y_la_enfermedad.pdf

Armus, Diego, "El descubrimiento de la enfermedad como problema social", en Mirta Lobato (dir.), El Progreso, la modernización y sus límites (1880-1916), Buenos Aires: Sudamericana, 2000.

— La ciudad impura. Salud, tuberculosis y cultura en Buenos Aires (1870-1950), Buenos Aires: Edhasa, 2007.

Barrio, Patricia, "Finanzas públicas y vitivinicultura durante el lencinismo. Mendoza 1923-1928”, en Folia Histórica del Nordeste, núm. 31, IIGHI-IH-CONICET/ UNNE, enero-abril, 2018, pp. 1-26.

, "Regulación e intervención estatal en tiempos turbulentos. El caso de la vitivinicultura mendocina entre 1918 y 1923”, en Rodríguez Vázquez, Florencia et al., De la regulación a la intervención en tiempos de cambio. Las prácticas y vínculos estatales en la provincia de Mendoza, 1916-1970, Rosario: Prohistoria Ediciones, 2014.

Ben Plotkin, Mariano y Zimmermann, Eduardo, Los saberes del Estado. Construcción de elites técnicas estatales en la Argentina, siglos XIX y XX, Buenos Aires: Edhasa, 2012.

— Las prácticas del Estado. Política, sociedad y elites estatales en la Argentina del siglo $X X$, Buenos Aires: Edhasa, 2012.

Berná Vaccarino, Natalia Elina, Obra pública del arquitecto Raúl Álvarez en Mendoza, tesina de grado, Mendoza, Universidad Nacional de Cuyo, Facultad de Artes y Diseño, 2011. Recuperado de https://bdigital.uncu.edu.ar/4594

Belmartino, Susana; Bloch, Carlos; Persello, Ana Virginia; y Carnino, María Isabel, Corporación médica y poder en salud. Argentina 1920-1945, Rosario: Centro de Estudios Sanitarios y Sociales (CESS), 1988. Recuperado de https://iris.paho.org/handle/10665.2/18746?locale-attribute=pt

Biernat, Carolina; Cerdá, Juan Manuel y Ramacciotti, Karina, La salud pública y la enfermería en la Argentina, Buenos Aires: UNQ, 2015, pp. 13-18.

Carbonetti, A; Rodríguez, M.; Rimonda, N. y Martina, C., "Las epidemias de cólera en Córdoba a través del periodismo: la oferta de productos preservativos y curativos durante la epidemia de 1867-1868, en História, Ciencias, SáudeManguinhos, núm. 2, 2007, pp. 405-419.

DOI: https://doi.org/10.1590/S0104-59702007000200002.

Carbonetti, A., "Historia de una epidemia olvidada. La pandemia de gripe española en la Argentina, 1918-1919”, en Desacatos, núm. 32, 2010, pp.159-174. Recuperado de http://www.scielo.org.mx/scielo.php?script=

Cerdá, Juan Manuel, "Mercado de trabajo y condiciones de vida en Mendoza a comienzos del siglo xx", en Mundo Agrario, núm. 6, Universidad Nacional de La Plata, Facultad de Humanidades y Ciencias de la Educación, Centro de Estudios Histórico-Rurales, 2006. Recuperado de http://www.mundoagrario. unlp.edu.ar/ 
Cirvini, Silvia, "El ambiente urbano en Mendoza a fines del siglo XIx. La higiene social como herramienta del proyecto utópico del orden", en M. Rodríguez Lapuente y H. Cerutti Guldberg (comps.), Arturo Roig. Filósofo e historia de las ideas, México: Universidad de Guadalajara, 1989.

, Nosotros los arquitectos, Mendoza: Ediciones ciudad y Territorio, Incihusa, CONICET, 2004.

, "Raul Jacinto Álvarez", en Cecilia Raffa (dir.), Arquitectos en Mendoza. Biografias, trayectorias profesionales y obras (1900-1960), Mendoza: FFyLUNCUYO, 2016. Recuperado de http://bdigital.uncu.edu.ar/9327.

, "La edificación 'contra temblores'. Aportes para la historia de la construcción sismorresistente en Argentina”, en Revista de Historia de América, núm. 128, 2001, pp. 141-163.

Cirvini, Silvia y Gómez Voltán José, "El cemento armado y la construcción sismorresistente en Mendoza-Argentina (1900-1930)", Libro de Actas del XIV Congresso Internazionale di riabilitazione del patrimonio. La conservazione del patrimonio artistico, architettonico, archeologico e paesaggisti, Matera, Italia, 2018, pp.1409-1436.

Hirschegger, Ivana, "La Escuela Mixta de Enfermeros de 1942: una apuesta a la profesionalización de la enfermería en Mendoza", en Trabajos y Comunicaciones, núm. 49, 2019. https://www.doi.org/10.24215/23468971e084 , "La Salud Pública frente a un Estado centralizado: establecimientos y servicios asistenciales en la provincia de Mendoza durante el primer peronismo", en Trabajos y Comunicaciones, núm. 44, 2016. Recuperado de http://sedici.unlp.edu.ar/bitstream/handle/10915/56234/Documento_completo. pdf-PDFA.pdf?sequence $=1 \&$ isAllowed $=\mathrm{y}$

Lacoste, Pablo, La Unión Cívica Radical en Mendoza y en la Argentina, 1890-1946, Mendoza: Ediciones Culturales, 1995.

Luis, Natalia, La alpargata en el espacio público. Los efectos de la política lencinista en el espacio público mendocino, tesis de doctorado inédita, Facultad de filosofía y Letras, UNCuyo, 2018.

, "Agua potable y red cloacal. La extensión de los servicios sanitarios en Mendoza durante las gobernaciones lencinistas (1918-1928)", en Revista de Historia Americana y Argentina, vol. 55, núm. 1, Mendoza, Argentina: Universidad Nacional de Cuyo, 2020, pp. 115-153. Recuperado de: http://revistas.uncu.edu. ar/ojs/index.php/revihistoriargenyame/article/view/3477/2780

Luis, Natalia y Aguerregaray, Rosana, “De 'culpables' a 'víctimas': expansión y profesionalización del sistema de salud en la provincia Mendoza a fines del siglo XIx y principios del xx”, en Salud Colectiva, vol. 16, 2020.

DOI: https://doi.org/10.18294/sc.2020.2129.

Mazzeo y Pollero, La mortalidad infantil en ambas márgenes del Río de la Plata en la primera mitad del siglo $X X$. ¿Dos orillas, dos realidades?, 10. Recuperado de www.redaepa.org.ar/sitio_anterior/viii/AEPA/B20/Mazzeo\%20y\%20Pollero. pdf

Mellado, Virginia, "La Liga Patriótica Argentina. Una aproximación a las redes asociativas de los elencos políticos y culturales de Mendoza (1919-1930)", en Entrepasados, Revista de Historia, núm. 16, Buenos Aires, 2007, pp. 1-19. 
Persello, Ana Virginia, Historia del radicalismo, Buenos Aires: Edhasa, 2007.

Ponte, Ricardo, La Fragilidad de la Memoria, Mendoza: Ediciones Fundación CRICYT, 1999.

— El Carmen. Hospital de la filantropía, 1895-2005, $1^{\circ}$ Edición, Capítulo 5, Mendoza: Unidad Ciudad y Territorio del INCIHUSA-CONICET: Obra social de Empleados Públicos de Mendoza, 2005.

Raffa, Cecilia, "El imaginario sanitario en Mendoza a fines del siglo xIx: obras de higiene y salubridad durante la intendencia de Luis Lagomaggiore (18841888)", en Historia Social y de las Mentalidades, vol. 2, núm. XI, 2007, pp. $173-200$

, "Políticas sanitarias y arquitectura de Estado en Mendoza: el Gran Policlínico Central (1938-1943)”, en Estudios Sociales del Estado, vol. 6, núm. 11, 2020. Recuperado de http://www.estudiossocialesdelestado.org/index.php/ese/article/ view/207.

Ramacciotti, K. (coord. dossier), "La profesionalización del cuidado sanitario. La enfermería en la historia argentina”, en Trabajos y Comunicaciones, núm. 49, 2019. DOI: https://doi.org/10.24215/23468971e081

Richard Jorba, Rodolfo, "Los gobiernos radicales de los Lencinas en Mendoza. Salud pública y vivienda popular, 1918-1924. Rupturas y continuidades con el orden conservador", en Avances del Cesor, núm. 9, Rosario, 2011, pp. 31-62.

DOI: https://doi.org/10.35305/ac.v8i08.832

, "Los orígenes del fenómeno populista en Mendoza. El gobierno de José N. Lencinas, 1918-1920”, en Florencia Rodríguez Vázquez et al., Gobernar la provincia del vino. Agroproducción y política entre la regulación y la intervención. Mendoza, 1916-1970, Rosario: Prohistoria Ediciones, 2014.

Rodríguez, Celso, Lencinas y Cantoni. El populismo cuyano en tiempos de Yrigoyen, Buenos Aires, Editorial Belgrano, 1979.

Sanz Gimeno, "Infancia, mortalidad y causas de muerte en España en el primer tercio del siglo xx (1906-1932)", en REIS, núm. 95, julio-septiembre, 2001. Recuperado de http://ih-vm-cisreis.c.mad.interhost.com/REIS/PDF/REIS_095_07.pdf 